Peter Adeniyi Alaba, Yahaya Muhammad Sani, Isah Yakub Mohammed

and Wan Mohd Ashri Wan Daud*

\title{
Insight into catalyst deactivation mechanism and suppression techniques in thermocatalytic deoxygenation of bio-oil over zeolites
}

DOI 10.1515/revce-2015-0025

Received May 7, 2015; accepted August 28, 2015; previously published online December 9, 2015

\begin{abstract}
The economic viability of the thermocatalytic upgrade of biomass-derived oxygenates is facing the challenge of low-quality products. This is because of leaching of active species, coking, and concomitant catalyst deactivation. These cumulate into the loss of catalytic activity with time on stream (TOS), which causes low degree of deoxygenation. Thus, this article reviews recent advances aimed at alleviating these setbacks to make the process viable for industrial scale-up. To understand the concept of catalyst deactivation and to offer solutions, the review scrutinized the deactivation mechanism diligently. The review also analyzes deactivation-suppression techniques such as nanocrystal zeolite cracking, hydrogen spilt-over (HSO) species, and composite catalysts (hybrid, hierarchical mesoporous zeolite, modified zeolites, and catalytic cracking deposition of silane). Interestingly, these deactivation-suppression techniques enhance catalytic properties mostly by reducing the signal strength of strong acid sites and increasing hydrothermal stability. Further, the approaches improve catalytic activity, selectivity, and TOS stability because of the lower formation of coke precursors such as polynuclear aromatics. However, despite these many advances, the need for further investigations to achieve excellent catalytic activity for industrial scaleup persists.
\end{abstract}

\footnotetext{
*Corresponding author: Wan Mohd Ashri Wan Daud, Department of Chemical Engineering, University of Malaya, 50603 Kuala Lumpur, Malaysia, e-mail: ashri@um.edu.my

Peter Adeniyi Alaba: Department of Chemical Engineering, University of Malaya, 50603 Kuala Lumpur, Malaysia Yahaya Muhammad Sani: Department of Chemical Engineering, University of Malaya, 50603 Kuala Lumpur, Malaysia; and Department of Chemical Engineering, Ahmadu Bello University, 870001 Nigeria

Isah Yakub Mohammed: Energy, Fuel and Power Technology Research Division, School of Engineering, The University of Nottingham Malaysia Campus, Jalan Broga, 43500 Semenyih, Selangor Darul Ehsan, Malaysia
}

Keywords: acidity; biomass; coke; deactivation; deoxygenation; zeolite.

\section{Introduction}

The use of fossil fuels in several sectors, such as heat and power generation, and transportation create environmental hazards from emission of greenhouse gases (Graça et al. 2010). Furthermore, these fuels are nonrenewable, often scarce with unpredictable prices. Also, because of the excessive use of these conventional fuels, crude oil exploration is said to have reached its peak (Mohammad et al. 2013). Thus, the public outcry for urgent solutions explains the need to seek alternative and sustainable sources of energy. Biomass from fast pyrolysis possess high potentials for producing biofuels and other specialty chemicals for replacing fossil fuel-derived products (Demirbas 2009, Botas et al. 2012). Techniques currently explored in producing these biofuels include thermal cracking (pyrolysis), coblending with VGO, and microemulsion of biomass (Gómez et al. 2013). Fast pyrolysis is the most commonly used method for biofuel production from biomass because it is economically viable and thermally efficient (Apaydin-Varol et al. 2014). The product of this process include gaseous, liquid, and solid biofuels. The liquid biofuel could be biocrude, synthetic oils, and biodiesels (Demirbas 2007a, 2008a,b, Gerçel and Gerçel 2007, Gonzalez et al. 2008, Ye et al. 2008, Balat 2009). However, the major drawback of biofuel from pyrolysis is the oxygen contents, which is responsible for its low heating value, instability, and high acidity (Pütün et al. 2006, Demirbas 2007b, Phung et al. 2012, Shi et al. 2014). This constituent lowers the quality of the biofuel and thereby restricts its application. Despite this, however, the popularity and the public acceptance of biofuels are on the increase. The major reasons for this include sustainability of fuels derived from renewable sources that support ecosystem and human heath as well as long-term goals on tolerable emissions. Other reasons include availability, 
environmental friendliness, accessibility, and reliability of the fuels (Demirbas 2007c, Quadrelli and Peterson 2007, Karki et al. 2008). Thus, several approaches are being explored to reduce the oxygen contents of this technique.

The hydrodeoxygenation (HDO) process is one of the useful methods for reducing oxygen contents and producing efficient biofuels. However, HDO is not economically feasible because it requires high pressure and large amounts of hydrogen derived from fossil fuels. These requirements cause negative effects on the carbon footprint of the bioprocess (Heeres et al. 2009, Bozell and Petersen 2010, Serrano-Ruiz et al. 2012). An alternative route for deoxygenating biofuels is thermocatalytic deoxygenation, which proceeds at lower temperature and atmospheric pressure without hydrogen. Similarly, catalytic cracking differs from $\mathrm{HDO}$ as it does not require the use of hydrogen at high pressure. However, short catalyst lifetime because of deactivation and low $\mathrm{H} / \mathrm{C}$ ratio hinders the industrial applicability of the process. This limitation leads to the production of low-grade fuels with lower heating value than fossil fuels (Chew and Bhatia 2009, Mortensen et al. 2011, Botas et al. 2012).

Conversely, mordenite framework inverted (MFI) structure catalyst has gained popularly in facilitating catalytic cracking. Attributes such as olefin selectivity, acidity, thermal stability, absence of cage at the pore intersection, and system of connected pores are some of the factors that ensure the popularity of this molecular sieves (Ibáñez et al. 2014). However, the microporosity of these materials hinders large molecules from accessing the active sites of the catalyst. Thus, mass transfer limitation restricts effective reaction. This leads to coke deposition on the zeolite crystal that causes deactivation. Therefore, the advantage of mesoporous aluminosilicates such as Santa Barbara Amorphous-type material, or SBA-15 (Zhao et al. 1998), and Mobil Crystalline Materials, or MCM-41 (Kresge et al. 1992), comes handy in minimizing this limitation. However, despite their mesoporosity, which allows diffusion of bulky molecules, lower acid strength and hydrothermal stability are restricting the wide acceptability of these materials (Castano et al. 2011, Liu et al. 2012). These challenges await the ingenuity of the academia and research community.

It is a known fact that catalysts do not remain active ad infinitum. In fact, it is this knowledge that led to numerous studies on how to "circumvent" the natural process of catalyst deactivation. As this search intensifies, it is appropriate that researchers do not lose sight of the fundamentals such as cause and effect. A major cause of concern in bio-oil upgrading is coke formation. Coke deposition during catalytic valorization of the bio-oil is of two types (Gayubo et al. 2010, Zhang et al. 2011). Coke is deposited on the catalyst micropores because of condensation, hydrogen transfer, and dehydrogenation reactions. This is called catalytic carbon. The other type is coke deposited on the catalysts matrix as a result of elevated temperature (Gayubo et al. 2010, Ibáñez et al. 2014). The former contributes more to deactivation than the latter (thermal carbon) mainly because it possesses lower hydrogen content (Mortensen et al. 2011, Jiménez-García et al. 2013). Figure 1 presents the kinetic scheme for coke formation. Similarly, steam-solid reaction also causes catalyst deactivation by the dealumination of aluminosilicate materials. This changes the morphology of the catalyst with consequent effect on its activity.

Despite the popularity and over six decades of research and development in fluid catalytic cracking (FCC), the process of crude oil refining, deactivation affects catalysts detrimentally with economic consequences. Deactivation occurs via the deposition of coke produced from cyclic intermediates as well as hydrothermally via steam-solid reactions (O'Connor and Pouwels 1994). This makes the extrapolation of the thermocatalytic upgrade of bio-oil from FCC nonviable in the same manner. Consequently, several researchers reported ways for minimizing catalyst deactivation rate. These include cofeeding with hydrogen source such as water, methanol, and tetralin into the reaction feed (Gayubo et al. 2009, Xie et al. 2010, Zhu et al. 2010, Rezaei et al. 2014). Another approach that is gaining attention is the synthesis of composite materials comprising hierarchical mesoporous zeolite and the hybrid of mesoporous aluminosilicate and microporous zeolites. The latter approach improves mass transfer through the pore of the catalyst and thermal stability from the combined strength from the hybridization (Xie et al. 2010). Despite

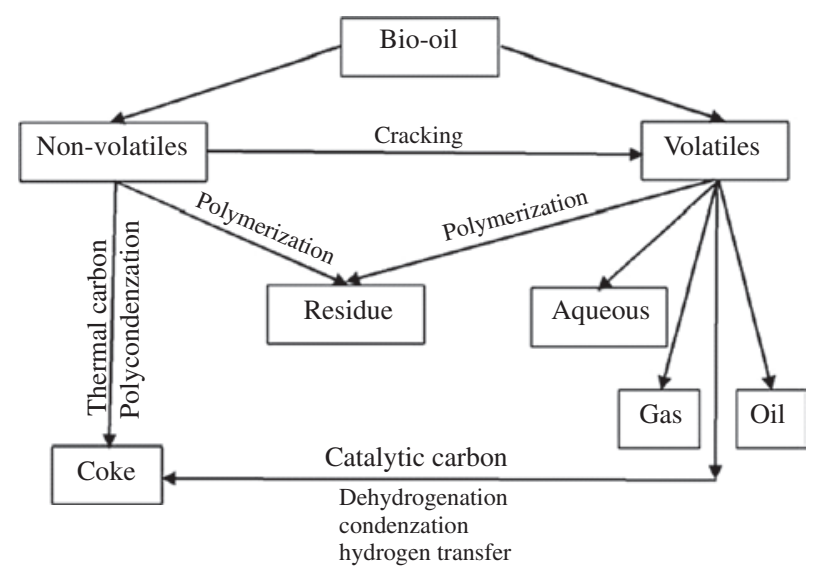

Figure 1: Kinetic model for bio-oil deoxygenation, showing coke routes adopted from Mortensen et al. (2011). 
these advances, catalyst deactivation is far from becoming a forgone problem. Reasonably, this is because hydrocarbon basicity has a significant effect on coke formation. This explains the phenomenon governed by carbonium ion rather than free radical mechanism (Eberly et al. 1966, Corma et al. 2007, Park et al. 2010). Thus, the aim of this review is to highlight methods for optimizing catalytic activities, increasing TOS stability, and degree of deoxygenation. To achieve this aim, we limited our analyses to studies on the deactivation mechanisms and emphasized on the suppression techniques in zeolite cracking. This is because of the importance of zeolite cracking and its wide applicability in bio-oil upgrading. The review presents a detailed analysis on deactivation mechanisms and analyzes recent approaches for lessening such limitations. These include the latest improvements in the thermocatalytic upgrade of biomass-derived oxygenates such as the use of hydrogen source, hierarchical mesoporous MFI, and other composite materials for reducing deactivation tendency.

\section{Deoxygenation over zeolites}

Microporous molecular sieve (MFI) possesses well-defined and elaborate pore structures with high surface area, acidity, and adsorption capacity. It selectively permits diffusion and conversion of molecules such as light olefins and aromatics (Mante et al. 2014). These attributes ensured wide industrial utilization on zeolites, especially in petrochemistry, oil refining, and production of fine chemicals (Huber et al. 2006, Huber and Corma 2007). Interestingly, catalytic deoxygenation over zeolites is similar to FCC, which also uses zeolite catalysts (Huber and Corma 2007). Hence, transferring the knowledge and expertise acquired from the latter onto the former would save time and cost. This is in addition to the economic advantage that catalytic deoxygenation enjoys as it proceeds at atmospheric pressure without hydrogen requirement.

Bio-oil is a synthetic fuel currently under experimentation as a potential substitute to fossil fuel. The pyrolysis of biomass at approximately $600^{\circ} \mathrm{C}$ produces the pyrolytic oil that contains a large amount of oxygen. However, the cracking of bio-oil by thermocatalytic deoxygenation over MFI is yet to attain industrial-scale acceptability. Low catalytic activity premised by mass transfer limitation and subsequent coke formation and associated high deactivation rate are the major factors hindering the prominence this process. Moreover, strong acid strength, a common feature of MFI catalysts for good catalytic activity, also promotes deactivation (Yan and Le Van Mao 2010, Duan et al. 2013, Zhang et al.2014). This led to keen interest in the use of other FCC catalysts such as FAU zeolite for biofuel production. FAU zeolites are characterized with strong acidity and wider pore than MFI. However, cracking with FAU zeolite is plagued with the formation of noncondensable gases and large amount of coke. This is attributed to the occurrence of bimolecular reaction, which promotes hydrogen transfer at the FAU zeolite matrix (Mante et al. 2014). Moreover, the quality of the biofuel obtained from zeolite cracking is lower than that of conventional fuel because of high oxygen content (Mortensen et al. 2011). The low value of the $\mathrm{H} / \mathrm{C}$ ratio indicates the products are aromatics with lower heating value when compared with that of fossil fuel. The mechanism of the thermocatalytic deoxygenation of bio-oil over zeolite is associated with decarbonylation, decarboxylation, and dehydration. The most common of these routes is dehydration. Bedard et al. (2012) proposed that methanol dehydration is initiated by the adsorption of the reactants on the active sites followed by either decomposition or bimolecular monomer dehydration (Figure 2).

Most thermocatalytic cracking processes operate at atmospheric pressure, temperature between $300^{\circ} \mathrm{C}$ and $600^{\circ} \mathrm{C}$, and gas hourly space velocity of $\sim 2$ (Mortensen et al. 2011). However, zeolite deactivation increases with increase in reaction temperature and time. This is because coke deposited on the internal and external surfaces of the catalyst is approximately $40 \mathrm{wt} \%$ of the feed (Huber et al. 2006). Conversely, the deoxygenation of light hydrocarbons occurs at elevated temperatures (Mortensen et al. 2011). Consequently, the major hydrocarbons (aromatics) produced at elevated temperatures are mostly coke precursors. They have the tendency of fouling the surface and pores of zeolite particle during cracking over conventional MFI zeolites. Nonetheless, high temperature is a requirement for a high degree of deoxygenation (Mortensen et al. 2011). These highlight the need to strike a balance between the required temperature and ensuring a coke-inhibited process. Fundamental knowledge regarding catalyst deactivation mechanism becomes imperative. Interestingly, solid basic sites are not affected by coking because they lack ability to crack (Sooknoi et al. 2008). However, they are susceptible to deactivation in steam medium because of their hydrophilicity nature, which emanates from steam condensation in the mesopores (Yonli et al. 2010). Thus, bio-oil upgrading also proceed over solid basic catalysts because an active catalyst requires both basic and acid sites in some cases. A perfect example is basic zeolites with a low $\mathrm{Si} / \mathrm{Al}$ ratio that conjugates acid-base pairs. The catalysts possess 


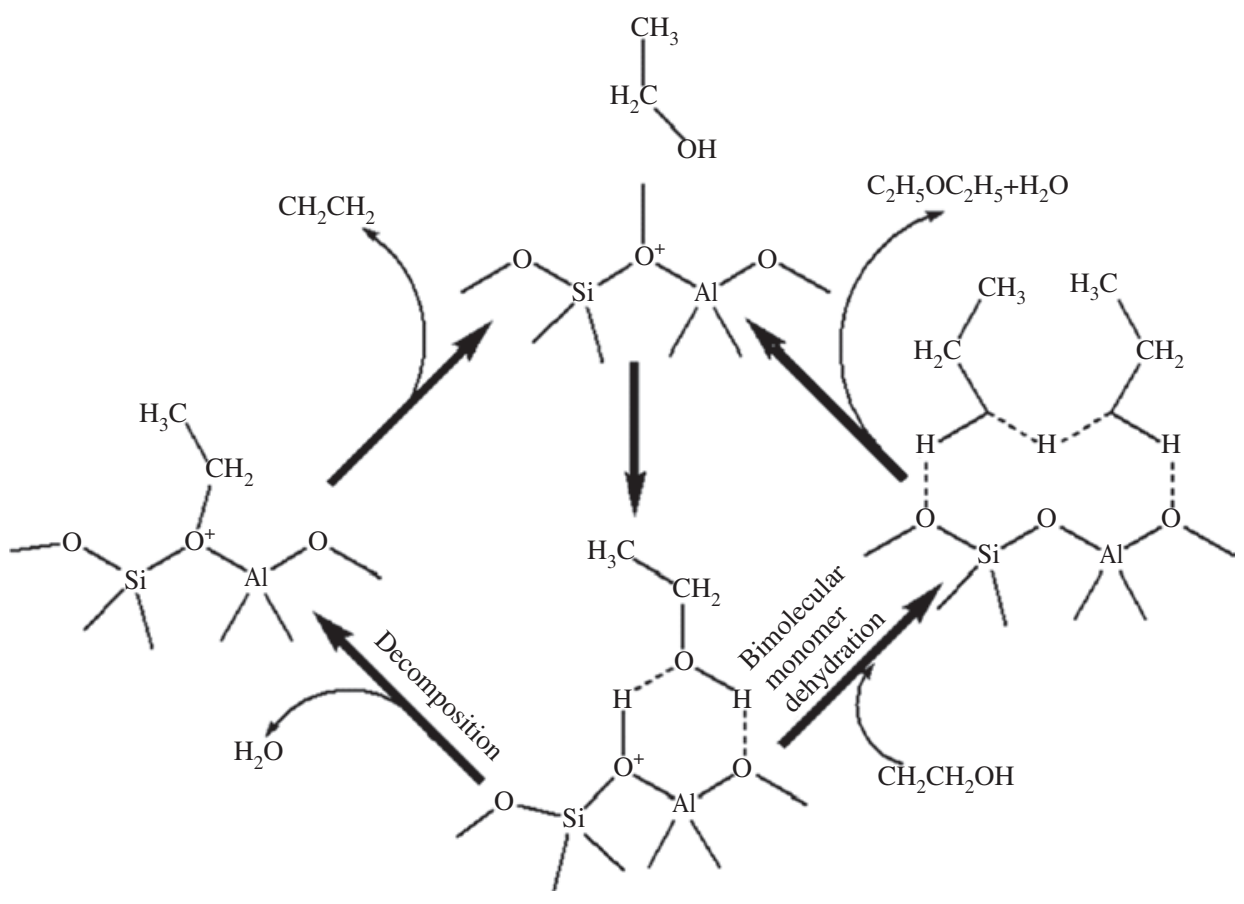

Figure 2: Dehydration mechanism of methanol over zeolites (Mortensen et al. 2011).

Lewis acid sites in the form of exchangeable cation near the oxygen in the zeolite framework. This represents the zeolite basic sites, which decarbonylate or decarboxylate the oxygenated feedstock to produce hydrocarbon (Barthomeuf 1996).

\section{Catalyst deactivation mechanism}

The two major limitations hindering the industrial-scale development of most catalytic processes are the leaching of active species (such as dealumination) and the deposition of carbonaceous material on the catalyst surface (Sooknoi et al. 2008). On the one hand, the deactivation mechanism in a catalytic system depends on the hydrothermal stability, acidity, and textural properties of the catalyst, the reaction type and condition, and the feedstock (Eberly et al. 1966, Bartholomew 2001, Corma et al. 2007, Park et al. 2010, Konno et al. 2013). On the other hand, microporous catalysts are mostly susceptible to deactivation because of the limited accessibility of the reactants to pore spaces. This decreases the number of acid sites with concomitant decline in catalytic activity. Intriguingly, temperature and acid site density play a significant role in both deoxygenation reaction and deactivation. These driving forces induce the leaching of active species and the formation of waxes and polyaromatics (Moulijn et al. 2001, Martínez et al. 2007,
Tago et al. 2011, Liu et al. 2012). Table 1 highlights some prominent causes of deactivation in various catalytic systems, and Figure 3 presents the two-step process for coke formation from bio-oil valorization. Surface intermediates from the initial reactant as well as the product in the gas phase produce coke precursors (Hajek et al. 2004, González et al. 2007, Kumbilieva et al. 2011). Further, steam generated from dehydration reaction also serves as a potential deactivating agent (Mante et al. 2014). These accumulate gradually on the catalyst and heighten the decline in catalyst performance because of blocked catalyst pores.

The following sections discuss the catalyst deactivation routes alluded to in the introductory section.

\subsection{Deactivation by catalytic carbon}

Catalytic carbon is the second step and the major source of catalyst degradation in bio-oil valorization because it blocks the acid sites directly, as presented in Figure 3 (Jiménez-García et al. 2013). This deactivation route involves the fouling of catalyst micropore surface by the deposition of coke or carbonaceous substance from the reacting system because of hydrogen transfer, condensation, aromatization, and cyclization reaction of oxygenates (Mortensen et al. 2011). Both Brønsted and Lewis acid sites influence the catalytic coke deposition on 


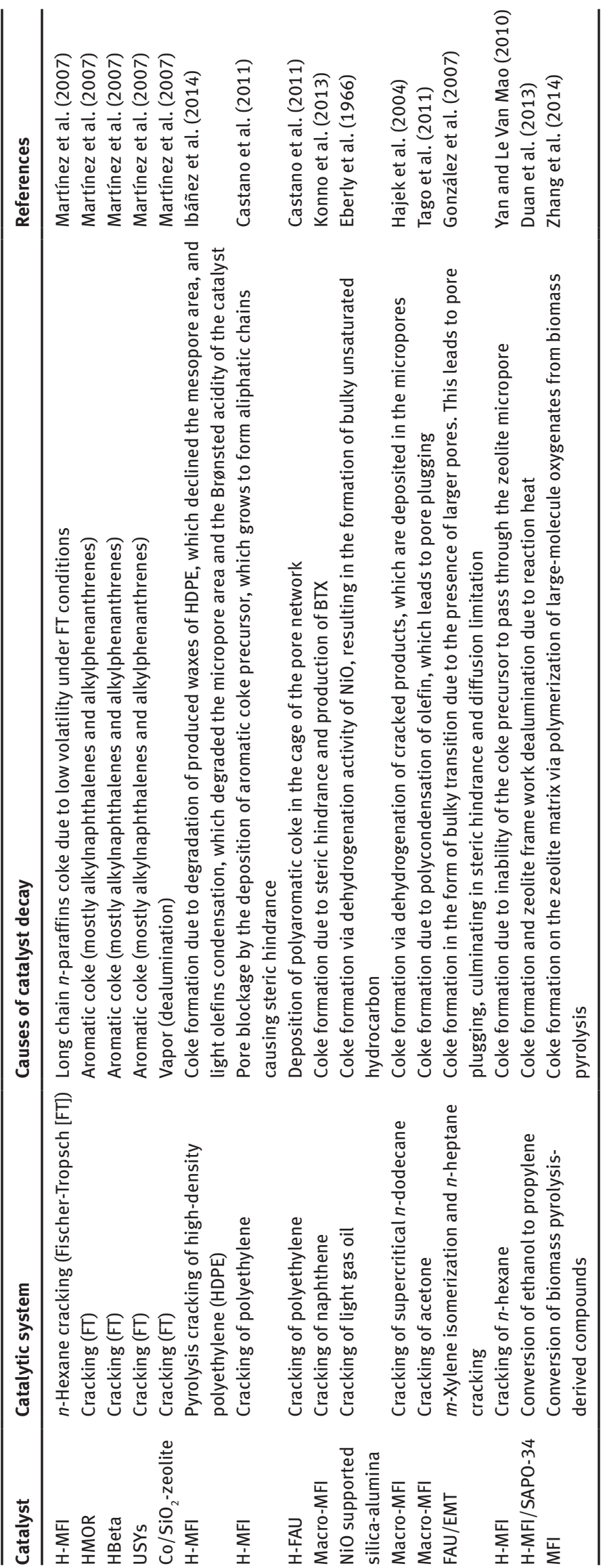




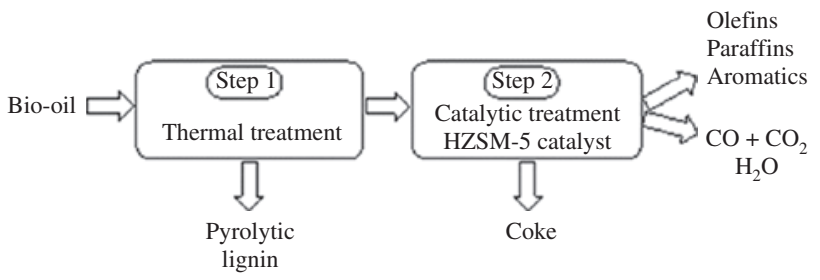

Figure 3: Two-step process for the formation of coke from bio-oil valorization adopted from Ibáñez et al. (2012).

zeolites. However, the influence of Brønsted acid sites is more critical (Niwa et al. 2012a, Castaño et al. 2013). This is because the Lewis acid sites bind the reacting species to the surface of the catalyst, while the Brønsted acid sites donate protons to the relevant compounds. Depending on the feed type and residence time, catalytic carbon coke formation is usually from bulky hydrocarbon or graphite. Pore constriction and blockage increases because of the mechanically deposited coke in the pores and internal acid sites (Hajek et al. 2004, Mortensen et al. 2011). Menon (1990) classified catalytic reactions based on catalytic carbon formation into (1) coke-sensitive reaction and (2) coke-insensitive reaction. Regarding the former, catalytic activity decreases because the nonreactive coke fouls the active sites of the catalyst micropores. Contrarily, coke-insensitive reaction leads to the formation of reactive coke precursors such as paraffin waxes and unsaturated cyclic hydrocarbons on the active sites of the catalyst. Hydrogen source or other gasifying agents remove such coke precursors easily and minimize deactivation (Zhu et al. 2010).

Coking in catalytic cracking is more of a coke-sensitive than a coke-insensitive reaction, depending on the pore size of the catalyst. If the catalyst is less porous, diffusion limitation facilitates the formation of reactive coke precursor, which hinders reacting species access to the catalyst active sites. These insights are paramount in minimizing catalyst deactivation because the acid sites of a catalyst are the driving force in the catalytic cracking of bio-oil. Further, the Brønsted acid sites serve as a source of hydrocarboncation by donating protons (Van Santen 1994). This process enhances the cracking potential and the aromatization reaction or polycondensation of aromatic species (Huang et al. 2009). This instance highlights the immense contribution of acid sites to deoxygenation reaction and the mechanism of deactivation. Therefore, to minimize deactivation and to optimize the degree of oxygenation, it is necessary to investigate how to modify the catalyst to minimize the amount of acid sites and crystal size (Moulijn et al. 2001).

\subsection{Deactivation by thermal carbon}

Elevated temperatures ensure increased cracking rate, high degree of deoxygenation, and high oil and gas yields during the catalytic upgrade of bio-oil. However, higher reaction temperature increases catalyst deactivation because of pyrolytic lignin (thermal carbon) formation, as presented in Figure 3 (Gayubo et al. 2009, Mortensen et al. 2011). Further, cracking at elevated temperature favors the polycondensation of the phenolic components of crude bio-oil. This forms carbonaceous materials (coke, which contains higher hydrogen content compared with catalytic carbon) that constrict the pores of the catalyst matrix (Gayubo et al. 2010). Consequently, reactants are obstructed from accessing the catalyst active sites (Jiménez-García et al. 2013). Aside the forgoing limitations, catalyst sintering occurs at temperatures higher than $500^{\circ} \mathrm{C}$, whereas the presence of steam aggravates steam-solid reaction (Bartholomew 2001). The following section discussed this steam-solid reaction in details. Therefore, to minimize thermal carbon and sintering, it is important to develop catalysts with high thermal and hydrothermal stability and also to ensure that reactions are within the optimum temperatures especially for hydrothermally stable catalysts (Moulijn et al. 2001). Thermal carbon also differs from catalytic carbon by their combustion behavior. According to the temperature program oxidation of coke combustion, thermal carbon burns at temperatures lower than $500^{\circ} \mathrm{C}$, whereas catalytic carbon burns at temperatures higher than $500^{\circ} \mathrm{C}$ (Ibáñez et al. 2012, Jiménez-García et al. 2013).

\subsection{Deactivation by steam-solid reaction}

Steam formation during bio-oil cracking and the subsequent transfer of such volatile phase from the reactor to the catalyst bed could stimulate the hydrothermal breakdown of the catalyst. Moreover, steam (a by-product via dehydration in bimolecular reaction) reacts with the catalyst to form ultimate gel particles (O'Connor and Pouwels 1994). The detrimental effect of steam-solid reaction manifests in the loss of crystallinity, BET surface area, porosity, and acidity (O'Connor and Pouwels 1994). This is evident in the dealumination of zeolitic Si-O-Al structure, which depends solely on hydrophobicity. However, the rate of hydrothermal deactivation depends on the hydrophobicity of the catalyst material (Martínez et al. 2007, Jacobson et al. 2013). For instance, zeolites with high hydrophobicity exhibit high hydrothermal stability. 
In this case, the steam competes with the alkane adsorption on the catalyst acid sites and induces the dealumination of the zeolite lattice (Bartholomew 2001, Moulijn et al. 2001). Fewer hydrophobic zeolites with a low Si/Al ratio such as FAU are more susceptible to steam attack in reaction medium. This has rather more effect on Brønsted acidity than on the Lewis, thereby reducing the $\mathrm{B} / \mathrm{L}$ ratio (Niwa et al. 2012b, Castaño et al. 2013). Further, corrosive reacting medium facilitates dealumination, especially if the catalyst $\mathrm{pH}$ level is $\geq 12$ or $<3$ (Moulijn et al. 2001). To reduce the influence of steam-solid reactions, rational design, and development of zeolites or solid acid catalysts with good hydrothermal stability, less corrosive $\mathrm{pH}(3 \leq \mathrm{pH}<12)$ becomes crucial. This could be achieved by ensuring the catalyst possesses higher mesopore/ external surface area because external acid sites are more hydrothermally stable than the internal acid sites (Kim et al. 2012).

\section{Deactivation-suppression strategies}

The search for means of minimizing deactivation is as old as the catalytic process development. In fact, deactivation has been the problem of zeolite catalytic cracking. However, a long-lasting solution has proved abortive. Moreover, there are different deactivation routes that easily deactivate active sites. These include reversible or irreversible chemical poisoning, physical fouling, thermal sintering, mechanical erosion or attrition, and vaporization of active materials (Bartholomew 2001, Moulijn et al. 2001). The impact of deactivation on the overall catalytic process economics is negative. It leads to low product yields, longer reaction times, reduced catalyst lifetime, financial implications in procuring new or reactivating aged catalyst, and increased labor. Therefore, efforts targeted toward suppressing this problem are advancing to ensure economic industrial process scale-up. These efforts include rational design and development of zeolite catalyst with high hydrothermal stability, acid site density, porosity, and mild acid and basic strength (Pütün et al. 2009, Yan and Le Van Mao 2010). This ensures increase in turn over frequency (TOF or number of molecule per active site) (Sani et al. 2014). It also inhibits fouling process by controlling polycondensation reaction and subsequently increasing catalyst lifetime (Yan and Le Van Mao 2010) and overall greater commercial value. The following subsections discuss instances of these approaches.

\subsection{Nanocrystal zeolite cracking approach}

Several nanocrystal zeolite cracking reaction studies exhibited superior performances (Taufiqurrahmi et al. 2010, 2011, Deng et al. 2011, Iwakai et al. 2011, Konno et al. 2013, Zhang et al. 2013, Sandeep and Saxena 2014) compared with conventional zeolites. This is evident from the high conversion and low coking tendency demonstrated by the former. These were because of minimal mass transfer gradient that allowed reactants and products to diffuse through shorter distances (Taufiqurrahmi et al. 2010, Louis et al. 2011, Liu et al. 2012, Rownaghi et al. 2012). Sandeep and Saxena (2014) studied various catalysts that exhibited different acidic and porous properties for the comparative cracking of Jatropha curcas oil. The authors used nanocrystalline MFI (NZ) approximately $90 \mathrm{~nm}$ with additional mesopore, beta zeolite (BEA), HFAU zeolite (large pore), and medium pore microcrystalline zeolite (MZ). The nanomaterials inhibited the cracking of higher olefins via dehydration, decarboxylation, decarbonylation, and cracking, which favor the formation of higher olefins. These olefins further undergo cyclization and dehydrogenation rather than cracking to form aromatics (Figure 4), thereby minimizing coke formation. The report revealed the following coke formation trend: NZ (1.9\%) < MZ (9.4\%)<BEA (14.7\%)<HY (32.1\%) (Table 2). This observation is due to the presence of mild acid strength and high acid density of NZ and MZ.

Likewise, NZ showed better performance than $\mathrm{MZ}$ because of extra mesoporosity and nanosized crystal that enhances shorter diffusion path for the products. Further, NZ exhibited higher TOS and stability in gasoline selectivity (approximately 78\%) for more than $20 \mathrm{~h}$ than the other catalysts. The catalytic cracking of $n$-hexane, cyclohexane, and methylcyclohexane deposited 7.1, 7.4, and 6.9 coke (wt\%), respectively, on macrocrystalline MFI $(\mathrm{Si} / \mathrm{Al}=150)$ after $4.5 \mathrm{~h}$. Conversely, the amounts (wt\%) of coke deposited on nanocrystalline MFI $(\mathrm{Si} / \mathrm{Al}=150)$ catalysts were 1.5, 2.8 and 5.1, respectively, after $4.5 \mathrm{~h}$. This highlights the effect of crystal size in minimizing catalyst deactivation. Similarly, studies by Konno et al. (2012, 2013) showed that nanocrystalline MFI shows stable catalytic activity and higher yield of olefins because of the fast diffusion of products through nanosized crystals. Results obtained from the catalytic cracking of $n$-hexane by Rownaghi et al. (2012) and acetone cracking over nanocrystalline MFI and macrocrystalline MFI by Tago et al. (2011) corroborated these findings. Similarly, Taufiqurrahmi et al. (2010) used nanocrystalline zeolite beta for cracking used palm oil. They reported that nanocrystalline zeolite beta exhibited high conversion of palm oil and gasoline yield. However, 


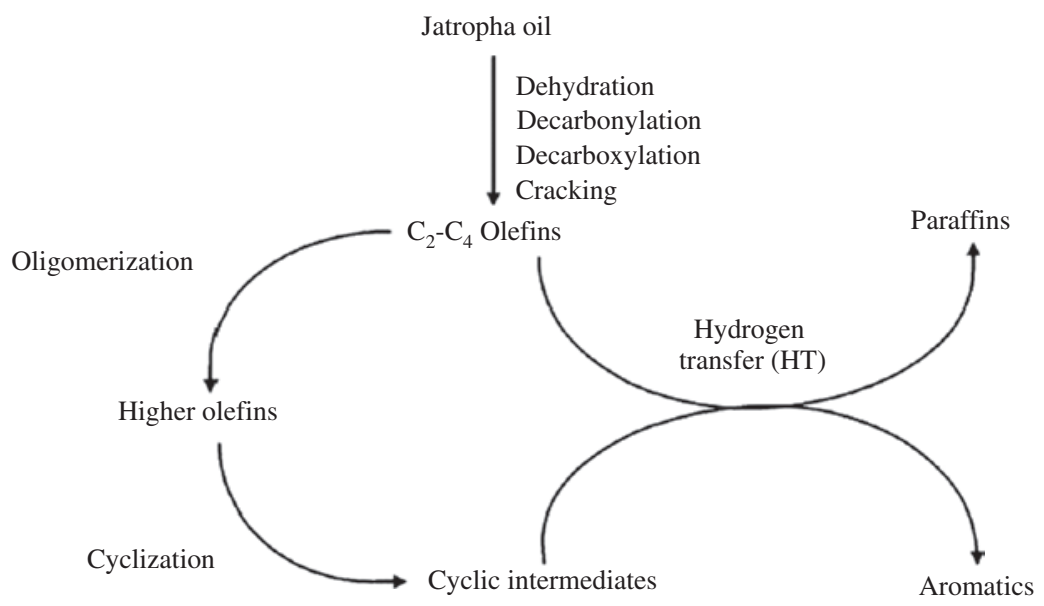

Figure 4: Reaction pathways for the formation of aromatics from Jatropha oil adopted from Sandeep and Saxena (2014).

the spent catalyst showed high coke content. Operating at elevated cracking temperatures solves this problem. The value of deactivation constant at $500^{\circ} \mathrm{C}\left(0.3091 \mathrm{~h}^{-1}\right)$, which is lower than deactivation constant at $400^{\circ} \mathrm{C}$ $\left(0.3813 \mathrm{~h}^{-1}\right)$, highlights this reduction. Mostly, nanoporous zeolites gain preference because of their short diffusion path lengths, minimized coking, and outstanding performances for cracking processes over conventional zeolites.

\subsection{Composite catalyst}

Composite catalysts with a synergistic combination of two or more components displayed remarkable catalytic activities, as shown in Tables 3 and 4. These composite materials include hybrid composites, hierarchical mesoporous composites, catalytic cracking deposition of silane, and crystallite composites obtained by cocrystallization and overgrowth. Encouraging results regarding this class of catalyst such as conversion, resistance to coking, as well as remarkable selectivity from catalytic processes are common in open literature (Twaiq et al. 1999, Tang et al. 2010, Xie et al. 2010).

\subsubsection{Hybrid catalyst cracking approach}

The search for robust and economic catalysts has led to advances such as hybrid catalysts. Currently, these catalysts have found applicability in the upgrade of biomassderived oxygenates and heavy hydrocarbon feedstock. The catalysts facilitate the efficient production of light olefins such as propylene and ethylene from naphtha and gas oils (Le Van Mao et al. 2001, Melancon et al. 2002, Yiu et al. 2005, Charusiri et al. 2006, Martínez et al. 2007, 2008,
Muntasar et al. 2010, Kang et al. 2012, Varzaneh et al. 2013, Yan 2013). Some techniques for synthesizing hybrid catalysts include the mixing or blending of catalyst and cocatalyst bound together with the help of a binder (Teng et al. 2011). The catalysts are generally dispersed within the matrix of the binder to produce a composite extrudate with improved strength and stability, which protects them against deactivation (Castaño et al. 2013, Whiting et al. 2015). Incorporating cocatalyst enhances synergistic activity and performance as well as complements of the parent catalyst by reducing its limitations. Extruding with inorganic binders such as pseudoboehmite and bentonite clay binds the different components of the catalyst together. Afterward, temperature treatment activates the active species of the hybrid catalyst (Muntasar et al. 2010). Mante et al. (2014) analyzed this phenomenon in the catalytic pyrolysis of biomass by investigating the effect of MFI composition as cocatalyst to FAU zeolite catalyst. The two zeolites were physically mixed after mild steaming at $732^{\circ} \mathrm{C}$. Interestingly, the hybrid catalyst produced a higher yield of organic liquid and a lower yield of coke and gas compared with its conventional FAU zeolite counterpart. In addition, higher MFI composition increases the $\mathrm{C}_{4}-\mathrm{C}_{5}$ and aromatic yield, with consequent decrease in the generation of $\mathrm{H}_{2}, \mathrm{CH}_{4}, \mathrm{CO}_{2}$, and aliphatic hydrocarbon.

Charusiri et al. (2006) investigated the effect of H-MFI, sulfated zirconia, and their hybrid in the cracking of used vegetable oil. The hybrid of H-MFI and sulfated zirconia exhibited higher aromatic selectivity and lower gasoline selectivity than the parent sulfated zirconia or H-MFI. This was due to coking suppression activity and higher stability with TOS (1.5 h) of the resultant hybrid catalyst. Further, the authors observed deactivation with the TOS of sulfated zirconia and H-MFI during vegetable oil cracking into aromatics. The study by Yan and Le Van 


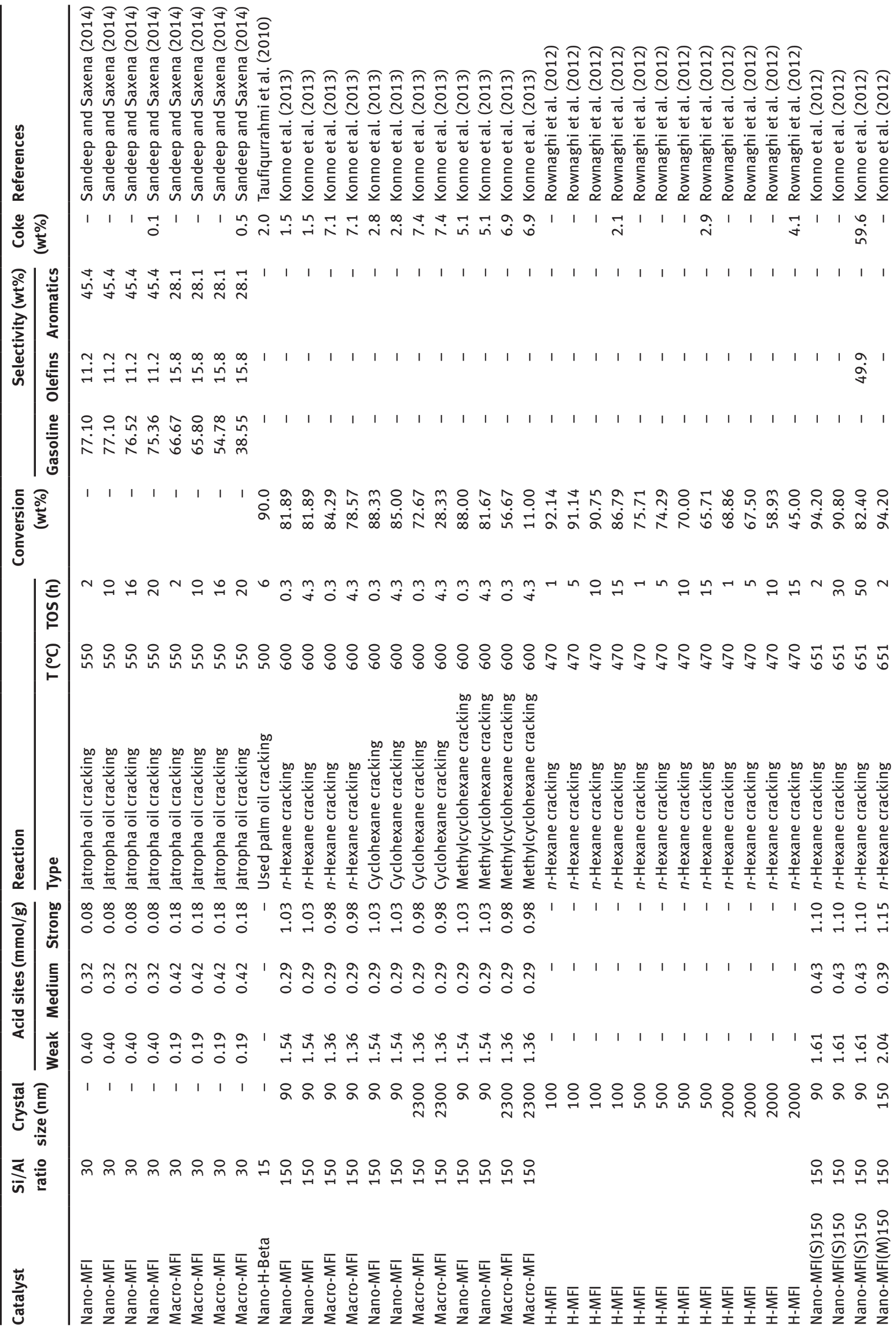


Mao (2010) also corroborated the fact that hybrid catalyst suppresses coking more than the corresponding reference catalysts (Table 3). The authors posited that coke precursors deposited on acid sites of zeolites migrate to the supported Ni-Ru promoter, which minimizes decomposition process at the openings of the zeolites pores. Thus, this reduces coke deposition on acid sites significantly. This confers outstandingly higher stability with increased TOS on the hybrid catalyst than the corresponding reference catalyst, which implies that the performance of the hybrid catalyst is dependent on the crystal size of the catalytic material. The studies of Le Van Mao et al. (2006, 2008) also confirmed this claim for thermocatalytic cracking over hybrid catalysts composed of Mo-supported alumina and supported Pt, Pd, and Ni cocatalyst. The hybrid catalysts produced the HSO species that possesses ring-opening features. Therefore, hybrid catalyst cracking approach offers synergistic performance by exhibiting mild acid strength and high acid density to achieve coke depression ability.

\subsubsection{Hierarchical mesoporous zeolite cracking approach}

Hierarchical mesoporous zeolites are composite materials with more than one level of porosity, for which the mesopore formation does not severely penalize the microporosity (Wang et al. 2010, Holm et al. 2011, Na et al. 2011, Ishihara et al. 2012). These mesoporous materials have wide acceptability in several industrial applications such as catalytic cracking (Aguado et al. 2008, Mei et al. 2008, Kim et al. 2010, Chen et al. 2012, Zhang et al. 2013, Zheng et al. 2013, Botas et al. 2014, Li et al. 2014a), Friedel-Crafts alkylations (Fan et al. 2008, Sun et al. 2008), phenol tertbutylation (Xu et al. 2008), and oxidation of benzene to phenol (Koekkoek et al. 2011). The design of hierarchical mesoporous zeolite is a proven approach through enhanced manipulation of microporous crystals in catalyst development such as hierarchical mesoporous MFI via the desilication of commercial MFI. The modified catalyst is efficient in mass transport as well as shape selectivity, and it exhibited a higher yield of aromatics with less coke when compared with the parent microporous MFI (Hartmann 2004, Perez-Ramirez et al. 2008). Further, the facile diffusion of coke precursors through the mesopore of the catalyst via short diffusion distances enhances the longevity of the catalyst (Li et al. 2014b). This minimizes fouling and enhances high catalyst reactivity due to enhanced mesopore area with accompanied remarkable hydrothermal stability of the external acid sites (Kim et al. 2012). 
Table 3: Remarkable performances of hybrid catalysts in varying configuration and reaction condition compared with reference catalyst (Yan and Le Van Mao 2010).

\begin{tabular}{|c|c|c|c|c|c|c|c|c|c|}
\hline \multirow[t]{2}{*}{ Catalyst } & \multirow{2}{*}{$\begin{array}{l}\mathrm{Si} / \mathrm{Al} \\
\text { ratio }\end{array}$} & \multirow{2}{*}{$\begin{array}{r}\text { Acidity } \\
\text { total }\end{array}$} & \multicolumn{3}{|l|}{ Reaction } & \multirow[t]{2}{*}{ Conversion } & \multicolumn{2}{|r|}{ Selectivity } & \multirow[t]{2}{*}{ Coke } \\
\hline & & & Type & $\mathrm{T}\left({ }^{\circ} \mathrm{C}\right)$ & TOS (h) & & Olefins & $\left(C_{3}=/ C_{2}=\right)$ & \\
\hline $\mathrm{Y}-\mathrm{AA} / 25 \mathrm{HYB}^{\mathrm{a}}$ & 22 & 0.32 & $n$-Hexane cracking ${ }^{c}$ & 552 & - & 78.5 & 76 & 1.32 & 15.7 \\
\hline $25 \mathrm{HYB}^{\mathrm{b}}$ & 22 & 0.37 & $n$-Hexane cracking ${ }^{c}$ & 537 & - & 80 & 1.49 & - & 24.9 \\
\hline Y-AA/50HYBa & 37 & 0.43 & $n$-Hexane cracking ${ }^{c}$ & 548 & - & 85 & 72.8 & 1.08 & 16.3 \\
\hline $50 \mathrm{HYB}^{\mathrm{b}}$ & 37 & 0.49 & $n$-Hexane cracking ${ }^{c}$ & 567 & - & 88.6 & 1.11 & - & 21.7 \\
\hline Y-AA/100HYB ${ }^{a}$ & 98 & 0.57 & $n$-Hexane cracking ${ }^{c}$ & 572 & - & 74.8 & 74.1 & 1 & 16.5 \\
\hline $100 \mathrm{HYB}^{\mathrm{b}}$ & 98 & 0.66 & $n$-Hexane cracking ${ }^{c}$ & 582 & - & 77.8 & 1.09 & - & 22.3 \\
\hline Y-AA/400HYB ${ }^{a}$ & 443 & 0.65 & $n$-Hexane cracking ${ }^{c}$ & 559 & - & 63.8 & 77.7 & 0.9 & 12.3 \\
\hline $400 \mathrm{HYB}^{\mathrm{b}}$ & 443 & 1.35 & $n$-Hexane cracking ${ }^{c}$ & 584 & - & 64 & 0.91 & - & 23 \\
\hline Y-AA/1000HYB ${ }^{a}$ & 765 & 0.67 & $n$-Hexane cracking ${ }^{c}$ & 567 & - & 63.2 & 78.7 & 0.9 & 13.4 \\
\hline $1000 \mathrm{HYB}^{\mathrm{b}}$ & 765 & 1.21 & $n$-Hexane cracking ${ }^{c}$ & 563 & - & 64.7 & 0.88 & - & 25.5 \\
\hline
\end{tabular}

aHybrid of Y-alumina aerogel and ZSM- 5 extrudate.

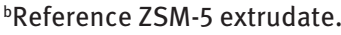

'Cracking of $n$-hexane contaminated with 1,2,4-trimethylbenzene.

These attributes made desilicated MFI zeolites prominent in aiding the fast pyrolysis of biomass. However, despite the optimum catalytic activity obtained with $0.3 \mathrm{M} \mathrm{NaOH}$ solution, severe desilication with $0.5 \mathrm{M}$ solution reduces the aromatic yield because of the severe penalization of microporosity evident from the larger mesopore volume.

The catalytic activity of hierarchical mesoporous zeolite depends on the hierarchy factor (HF) (PérezRamírez et al. 2009, Zheng et al. 2010, 2011, 2013, Koekkoek et al. 2011) and the crystal size of the catalytic material (Bjørgen et al. 2008, Viswanadham et al. 2012, Zhang et al. 2013, Yin et al. 2014). HF is a viable tool for categorizing the degree of the structural order of porous materials. Botas et al. (2014) reported improved accessibility and mass transport in the catalytic deoxygenation of rapeseed oil over nanosized hierarchical mesoporous zeolite modified with nickel. The study highlighted how the catalyst prevented further reaction of the cracked product. Interestingly, the nanosize particles of the catalyst crystal boost accessibility that concomitantly minimizes catalyst deactivation. Furthermore, at elevated temperature, the selectivity of light olefin is much higher than that of the aromatics. The short diffusion path length suggests high hydrogen content in the gaseous stream, which reduces the formation of catalytic coke from condensation, hydrogen transfer, and dehydrogenation reactions. However, the presence of nickel on the catalyst aids dehydrogenation activity, which leads to the formation of more aromatics in the system. Consequently, it is preferable to use nickel-modified hierarchical nanoporous zeolites that could promote dehydrogenation in the absence of external hydrogen sources for enhanced selectivity toward aromatic.
The claim that hierarchical nanoporous zeolites are remarkable catalysts of choice is in order. This is even more obvious with higher catalytic performances and coking suppression capabilities reported thus far. It is however interesting to note the linear relationship between the thermocatalytic cracking activity of hierarchical mesoporous zeolite and the HF with the number of Brønsted acid sites. Zheng et al. (2011, 2013) corroborated this linear relationship in their study of isopropyl benzene catalytic cracking over hierarchical mesoporous zeolites (MFZ) with the same composition and closely related acidities. The authors observed that catalysts with higher HF often exhibit higher catalytic performances when compared with other catalysts synthesized from similar precursors (Table 4). The higher catalytic performance of BEA with a lower HF was ascribed to its higher amount of Brønsted acid sites. Therefore, it is tenable to adduce $\mathrm{HF}$ and Brønsted acidity as the major determinants of catalytic activity. The performances of mesoporous zeolites (BFZ) in methanol dehydration attested to this claim (Table 4). Eq. (1) is the expression for obtaining HF:

$$
\mathrm{HF}=\frac{V_{\text {micro }} S_{\text {meso }}}{V_{\text {total }} S_{\text {BET }}},
$$

where $V_{\text {micro }}$ is the micropore volume, $V_{\text {total }}$ is the total pore volume, $S_{\text {meso }}$ is the mesopore surface area, and $S_{\mathrm{BET}}$ is the BET surface area.

Microspherical zeolite with intracrystalline mesopores is another good example of hierarchical mesoporous zeolite because of its mesoporosity and nanosized particles, which engenders short diffusion path and enhances accessibility to the active sites. Owing to these advantages, this technique offers remarkable catalytic activity 


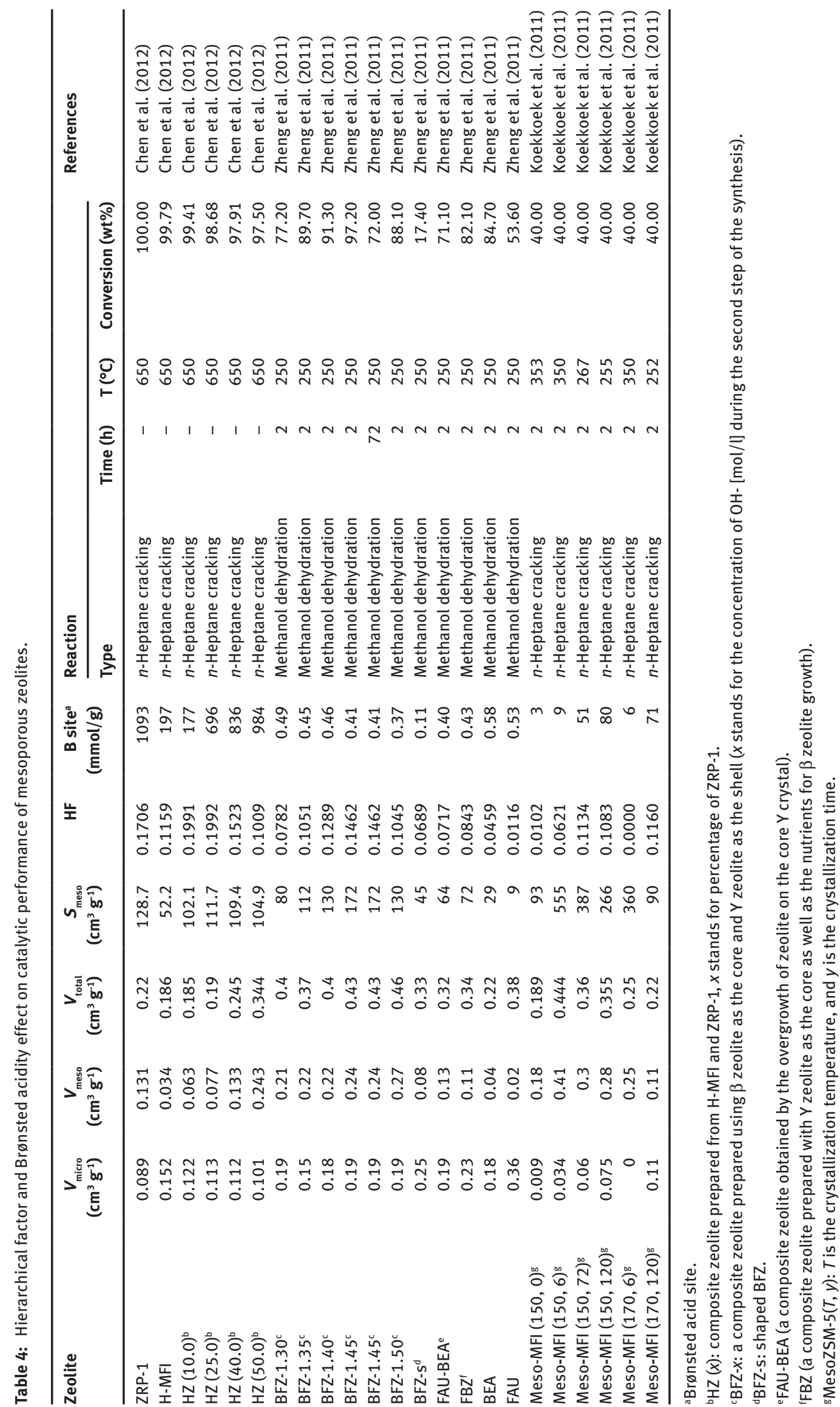


for the catalytic conversion of bulky molecules, facilitates high selectivity toward aromatics, minimizes coke formation, suppresses deactivation, and enhances TOS stability (Xue et al. 2012a,b, Na et al. 2013).

\subsubsection{Composite zeolites by intergrowth/overgrowth approach}

Predictably enough, composite materials with one or two levels of porosity (micro/microporous micro/mesoporous) synthesized via intergrowth or cocrystallization are prevalent in the open literature prevalent within the field of energy because of their synergistic performances (González et al. 2007, Wang et al. 2007, Liu et al. 2008, Tian et al. 2009, Duan et al. 2013). Examples of these composite materials include the core-shell composite of Ti-/Cr-AFI molecular sieve (Tian et al. 2009) and H-MFI/SAPO-34 (Duan et al. 2013). Others are MAZ/MFI (Wang et al. 2007), intergrowths of MCM-49/ MFI (Liu et al. 2008), FAU/EMT (González et al. 2007), and MFI/MEL (Francesconi et al. 2005), and overgrowth of MFI/ MOR (Al-Shammari et al. 2014). These composite materials have found wide acceptability in major catalytic processes because of their multistructural composition and outstanding performances (Xie et al. 2010). Recently, Duan et al. (2013) compared the performances of the composite hybrid of H-MFI and SAPO-34 with respect to the synthesis method. These include cocrystallization and physical mixing specifically for ethanol conversion in isothermal fixed bed reactor. Interestingly, composite HMFI/SAPO-34 (weight ratio=1 and HMFI Si/Al ratio=25) synthesized via cocrystallization exhibited outstanding performance because of its mild acidity and minimal coke deposition.

Conversely, the coking and dealumination of zeolite framework because of the strong acid strength deactivated the composite prepared via physical mixing. Nonetheless, the authors observed improved stability at temperature difference of $48^{\circ} \mathrm{C}$ between the top and the bottom, and $16^{\circ} \mathrm{C} / \mathrm{cm}$ temperature gradient in nonisothermal fixed bed reactor. Lower temperature at the top of the catalyst bed prevents drastic coking, whereas steady temperature increase below the catalyst bed allows the cracking of heavy hydrocarbons into lighter ones. Similarly, Wang et al. (2007) studied the catalytic performance of mazzite and MFI zeolite (MAZ/MFI) composite modified with zinc for FCC gasoline aromatization. The authors prepared the two composite materials with different levels of acidity: $\mathrm{Zn}-\mathrm{H}-$ MAZ/MFI (high acidity) and Zn-DA-MAZ/MFI (low acidity). Because of its mild acid strength, the coke deposited on $\mathrm{Zn}$ DA-MAZ/MFI was $0.10 \mathrm{wt} \%$ against $0.14 \mathrm{wt} \%$ deposited on Zn-H-MAZ/MFI. Consequently, the former exhibited more stability with remarkable selectivity toward aromatics than the latter. It is therefore rational to extrapolate the same configuration to the thermocatalytic cracking of bio-oil.

\subsubsection{Modified zeolites approach}

Zeolite surface modification with metal or metal oxide and phosphorus oxide is gaining considerable attention recently (Caeiro et al. 2006, Xue et al. 2010, Derewinski et al. 2014). Such modifications passivate the acid sites on the zeolites external surface for enhanced catalytic reactions. This decreases the strong acid sites, which makes the catalyst less affected by coke formation, and boosts the catalytic activity of the zeolite materials with prolong lifetime (Xie et al. 2010). Xue et al. (2010) reported the effect of phosphoric acid modification and alumina binder on HMFI for propane cracking. Infrared spectra and ${ }^{1} \mathrm{H}$ magic angle spinning NMR spectroscopy (MAS NMR) of the modified catalyst revealed a decrease in Brønsted acid site because of acid dealumination. The absence of Brønsted acid sites was evident in bridging $\mathrm{OH}$ group condensation with $\mathrm{POH}$ groups. This decreases the acid strength of the catalyst. The study by Derewinski et al. (2014) corroborated these findings. Tsai et al. (2007) also reported similar outstanding performance from the cracking of xylene and ethylbenzene over platinum MFI. Impregnating platinum into MFI inhibits secondary reaction that favors coke formation. It also improves ethylbenzene conversion and catalyst stability. Botas et al. (2012) investigated the influence of modifying hierarchical nanoporous MFI with nickel for the upgrade of rapeseed oil to biodiesel, raw chemicals, and carbon nanotubes. The authors observed coke formation in the form of carbon nanotube from the nickel nanoparticles. Similarly, the basicity of solid basic zeolites improves when supported with other materials. Gómez et al. (2013) increased the basicity of zeolite by impregnating it with cesium oxide $(\mathrm{CsOH})$ and potassium oxide (KOH) and used solid basic Na-FAU zeolite for the deoxygenation of methyl octanoate $\left[\mathrm{CH}_{3}\left(\mathrm{CH}_{2}\right)_{6} \mathrm{COOCH}_{3}\right]$. The modified zeolite exhibited good catalytic activity (85\% conversion and 3.6 desired/undesired product ratio) and approximately $51 \%$ selectivity of the desired $\left(\mathrm{C}_{6}, \mathrm{C}_{\vec{p}}\right.$ and $\mathrm{C}_{8}$ ) hydrocarbons due to the decrease in the electronegativity of the exchangeable cation in the Na-FAU zeolites. Seemingly, the dealumination of the catalyst in the reaction medium and the concomitant reduction in BET surface area triggers the loss of catalytic activity in basic zeolites. Consequently, the catalytic performance of solid base zeolite decreases with a higher Si/Al ratio. This indicates that the performance of catalysts produced by this 
approach is solely dependent on the hydrothermal stability and the $\mathrm{Si} / \mathrm{Al}$ ratio.

Further, functionalizing external surface with hydrophobic materials enhances the performance of solid basic catalysts. This preserves the structure as well as the active sites of the catalysts against detrimental effects such as deactivation that is associated with steam interaction in the reaction medium. Other techniques for enhancing hydrophobicity include silylation with organosilanes (Zapata et al.2012) and dealumination with $\mathrm{SiCl}_{4}$ via silicon exchange reaction (Kawai and Tsutsumi 1992). Zapata et al. (2012) modified the surface of H-FAU zeolites with organosilanes for the upgrade of biofuel. The modification enhanced the hydrophobicity of the zeolite and enabled it to stabilize water/oil emulsions, which improved the catalytic activity. The modified zeolite gives better catalytic activity ( $88.1 \%$ conversion) than the untreated zeolite (25.9\% conversion) in the upgrade of 2-propanol to propylene. The authors observed that although the textural and acid properties of the untreated H-FAU zeolite decline within a few hours in liquid medium at $200^{\circ} \mathrm{C}$, the modified H-FAU zeolites retained their acid density, surface area, crystallinity, and microporosity. Equally, Kawai and Tsutsumi (1992) modified Na-FAU zeolite by treating it with $\mathrm{SiCl}_{4}$ under dealumination silicon exchange reaction. The authors evaluated the hydrophobicity character of Na-FAU zeolite and the modified zeolite by measuring the heat of immersion in water and compared them with that of MFI zeolites. Interestingly, the heat of immersion of the modified zeolite was closely akin to that of the MFI zeolites. Moreover, the amount of water adsorbed on the modified Na-FAU zeolite was smaller than that of the unmodified zeolite. This further affirmed that functionalizing with $\mathrm{SiCl}_{4}$ has the potential for improving $\mathrm{FAU}$.

\subsubsection{Catalytic cracking deposition approach}

The catalytic cracking deposition (CCD) method involves reducing the pore size of zeolite by depositing cracked species on its external surface using coke deposition techniques (Masuda et al. 2001). The species include silane compounds such as $\mathrm{SiH}_{4}$, dimethyloctadecylchlorosilane, octadecyltrichlorosilane, phenyl-silane, triphenyl silane, and methyldiethoxysilane (MDES). The method reduces the acid strength of the catalyst via selective deactivation process by hindering reactants from accessing both strong and weak acid sites (Tago et al. 2011, Hong et al. 2013). In the interim, the first modification may not have considerable effect on the strong sites as much as on the weak sites. However, subsequent modifications lower the strong sites considerably, but such modifications have negligible effect on the weak sites (Hong et al. 2013). In a study by Hong et al. (2013), MDES $\left(\mathrm{C}_{5} \mathrm{H}_{14} \mathrm{O}_{2} \mathrm{Si}\right)$ molecule containing $\mathrm{Si}^{-} \mathrm{CH}_{3}$, $\mathrm{Si}-\mathrm{OC}_{2} \mathrm{H}_{5}$, and $\mathrm{Si}-\mathrm{H}$ groups produced $\mathrm{CH}_{4}, \mathrm{C}_{2} \mathrm{H}_{5} \mathrm{OH}$, and $\mathrm{H}_{2}$, respectively. Chemisorption and decomposition processes crack silane compounds within temperature range that corresponds to their bond energies $\left(-550^{\circ} \mathrm{C}\right)$, whereas complete decomposition by oxidation forms $\mathrm{SiO}_{2}$ (Hong et al. 2013). This approach is common in the modification of zeolite membranes with microporous structures. Further, it is evident in reactions performed at high temperatures, such as water-gas shift, and in the separation of chemicals, such as ethanol-water mixture, and xylene isomers (Choi et al. 2009, Shan et al. 2011, Wang and Lin 2012, Zhang et al. 2012, Wang et al. 2014). Interestingly, the CCD method has the potential for suppressing coke formation from zeolites with mesoporous membranes during the deoxygenation of bio-oil. Consequently, the technique is gaining the attention of researchers, especially in shape selectivity and size exclusion (Wang and Lin 2011). This is because lowering the signal strength of strong acid sites favors TOS stability and enhances catalytic activity (Tago et al. 2005).

Tago et al. (2011) worked extensively on MFI modification and reported higher acetone conversion, higher olefins yield, and lower aromatics yield from silylated MFI than with unmodified MFI. Introducing silane into a fixed bed reactor at $100^{\circ} \mathrm{C}$ and atmospheric pressure in a nitrogen stream to interact with the zeolite produced strong acid site with lower signal strength. After injecting the needed amount of silane, the authors removed the physically absorbed silane species from the surface of the zeolite. Increasing the temperature to $550^{\circ} \mathrm{C}$ in nitrogen stream for $1 \mathrm{~h}$ decomposes the chemosorbed silane species into a composite of silicon and coke. This process oxidizes the composite into $\mathrm{SiO}_{2}$. The procedure was repeated in three cycles to attain the targeted configuration for coking suppression. Figure 5 shows the effect of modification on the signal strength of the acid sites. Although CCD is a more recent approach, it has proven a viable strategy for reducing coke-forming tendency in thermocatalytic cracking. This is because the deposition of $\mathrm{SiO}_{2}$ from cracked silane compounds on the external surface of the catalyst reduces Brønsted acidity. However, this modification is tedious because it requires two or more cycles to achieve the desired configuration.

\subsection{HSO approach}

Within the field of energy, several instances that discussed the use of the HSO species for minimizing catalyst 


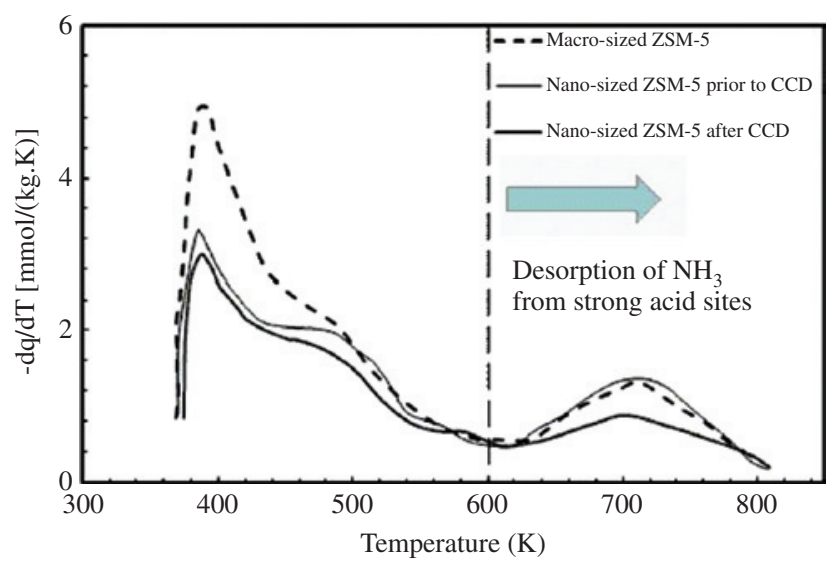

Figure 5: $\mathrm{NH}_{3}-\mathrm{TPD}$ profiles of the nanosized ZSM-5 before and after CCS modification adopted from Tago et al. (2011).

deactivation abound (Yan and Le Van Mao 2010, 2012, Prasomsri et al. 2011). The HSO species generates Brønsted acid sites that act as active sites for catalytic reaction (Zhang et al. 1995). The sources of hydrogen sources includes tetralin, decalin, methylcyclohexane, benzene, polymethylbenzene (1,2,4-trimethylbenzene), and alcohol (Gayubo et al. 2009, Yan and Le Van Mao 2010, 2012). The HSO species reacts with intermediates of catalytic deoxygenation reaction on the catalyst surface. This makes a significant impact on the catalyst by retarding the formation of coke precursors (Yan and Le Van Mao 2009). Valle et al. (2012) reported the efficacy of cofeeding bio-oil with methanol for efficient valorization. The authors asserted that the system proceeds in a similar reaction condition to that of methanol conversion into hydrocarbon. The addition of approximately $70 \mathrm{wt} \%$ of methanol helps to stabilize the system, attenuate the deposition of thermal carbon on the catalyst matrix, and reduce deactivation (Figure 6) (Valle et al. 2012). However, fundamental knowledge is required in selecting non-oil-derived hydrogen sources for this approach. A suitable hydrogen source encourages the desorption of the HSO species and controls the dehydrogenation of coke precursors to retard coke deposition (Prasomsri et al. 2011). It also promotes deoxygenation via decarbonylation rather than dehydration (Mentzel and Holm 2011). Furthermore, rapid coking occurs where the hydrogen source has stronger adsorption capacity than the feedstock (Yan and Le Van Mao 2010). Consequently, it is important to note that propylene and polymethylbenzene such as 1,3,5-trimethylbenzene are not suitable hydrogen sources owing to their strong adsorption property (Yan and Le Van Mao 2010, Prasomsri et al. 2011).

Yan and Le Van Mao (2010) studied the influence of the HSO species on MFI hybrid with Ni cocatalyst in catalytic steam cracking (CSC) using 1,2,4-trimethylbenzene as hydrogen source. The authors reported that the HSO species showed coke-cleaning action on the hybrid catalyst by interacting with the coke precursor. The interaction minimizes coke deposition, which increases the stability of the catalyst. The report of Gayubo et al. (2009) does not only agree with this but added that cofeeding methanol also minimizes $\mathrm{CO}$ and $\mathrm{CO}_{2}$ yields. This is because the HSO species formed on the surface of the supported $\mathrm{Ni}$ cocatalyst migrates to the main catalyst surface to partially or completely hydrogenate or decompose the bulky molecules. Hybrid catalysts with a low $\mathrm{Si} / \mathrm{Al}$ ratio and dehydrogenation or hydrogenation components such as $\mathrm{Ni}$ and Pt are often used in the HSO species approach (Yan and Le Van Mao 2012). The surface of supported metal or metal oxide cocatalyst of the hybrid catalyst generates active hydrogen species. These are spilt over the external surface of the main catalyst active sites to open the rings of some bulky hydrocarbons of the reactants and/or intermediates to inhibit the formation of polynuclear aromatics (Yan 2009, Yan and Le Van Mao 2009). This proposed intervention of cofeeding methanol into the process stabilizes the bio-oil. It is therefore plausible to assert that the HSO species assists in cleaning hybrid catalysts used in the catalytic cracking of biomass-derived oxygenates. This is helpful in producing lower aromatics and other heavy

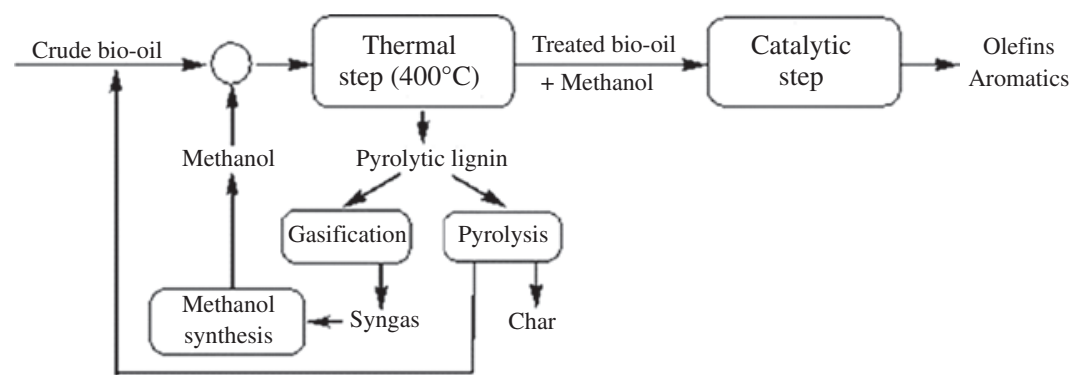

Figure 6: Two-step process for the transformation of crude bio-oil into hydrocarbons by cofeeding with methanol adopted from Valle et al. (2012). 
hydrocarbons, improving light olefins yields and ensuring remarkable stability at long TOS especially in fixed bed reactors (Yan 2009). Consequently, the reaction configurations successfully used in CSC and FCC are applicable in the thermocatalytic deoxygenation of biomass-derived oxygenates.

Prasomsri et al. (2011) studied the effect of the HSO species on HY and H-MFI zeolite catalysts in the catalytic conversion of biomass-derived oxygenates (anisole) with tetralin as the hydrogen source. The authors reported that incorporating tetralin into the feed inhibits deposition (adsorption) of phenol on the surface of the catalyst. The study also compared the effect of other hydrogen sources such as benzene, $n$-decane, and propylene and posited tetralin as the source with the highest hydrogen transfer capacity. Moreover, the study revealed the adverse effect that propylene has on the catalytic activity of the catalyst. Further, Beauchet et al. (2011) also examined the influence of tetralin in the catalytic deoxygenation of waste from biomass for producing fuel over Raney nickel. The tetralin solubilized the biomass waste at $330^{\circ} \mathrm{C}$, while the $\mathrm{HSO}$ species prevented the intermediates from undergoing recondensation reaction. Accordingly, the reduction in deactivation rate by the HSO species is of paramount importance in suppressing coking. In addition, it helps to minimize catalytic carbon, to maximize the yield of light olefins, and to depress that of aromatics with concomitant increase in TOS stability (Le Van Mao et al. 2008). Although the HSO approach has great potentials for retarding coke formation, there is the need for further research to discover the possibility of side reactions.

\section{Conclusion and outlook}

It is obvious from the foregoing that porosity, strong acidity, and steam (produced as by-product that dealuminates the surface structure of zeolites and other aluminosilicates) are some of the major limitations confronting the deoxygenation of bio-oil. Two general mechanisms of coke formation that decrease catalytic activity are the polycondensation of nonvolatile heavy oxygenated compounds in bio-oil, which forms thermal coke deposited externally, and the formation of catalytic coke deposited within the catalyst pores. Coke formation from the polymerization of oxygenated compounds is the major reaction competing against aromatization of oxygenated compounds. It is pertinent therefore to develop the means for minimizing these challenges. A critical analysis of the literature suggests reducing the strong signal strength of the acid sites of the catalyst because increase in acid strength increases the rate and extent of coke formation. In addition, advances on the basic zeolites maximize hydrophobicity and minimize deactivation by dealumination. Others suggest the use of nanoporous materials plausibly because the decrease in crystal size reduces the diffusion path length with concomitant decrease in the yield and concentration of coke. In addition, hydrothermally stable hybrid catalysts, hierarchical mesoporous zeolites, CCD, composite zeolites, and aluminosilicates with intergrowths, externally modified and hydrogen split over, are gaining attention. It is distinctly evident that these strategies offer remarkable performances in reducing deactivation tendencies. However, the need to explore a combination of two or more of these approaches simultaneously is logical. This is because coke formation is rather complex, involving a series of reactions from the extensive dehydrogenation of fused aromatic rings and the formation of polynuclear aromatics. Further, the morphology and structure of the catalyst also affects the deactivation mechanisms. For instance, the formation of polyaromatic species within the pore of $\mathrm{H}$-FAU, $\beta$-zeolites (large pore size), deactivates the zeolite catalysts, whereas the deposition of unsaturated coke on the external surface deactivates MFI (medium pore size). Overall, this review highlighted the need for further investigations before any approach could achieve excellent catalytic activity with coking suppression capacities for industrial scale. The authors also deem the following outlook worthy of research:

- Combined approach: using catalytic materials with different formulations such as hierarchical nanoporous zeolite with phosphorus modification and the HSO species approach. A different approach is to combine phosphorus modified nanoporous hybrid catalyst and HSO species. In addition, a combination of cracking with nanocomposite zeolites by intergrowth with phosphorus modification and the HSO species is another potential approach.

- Explore new catalyst formulations via rational catalyst design and development. This requires the use of real-time systems in combination with DFT to have improved understanding of coke formation mechanisms.

It is our conviction that although preventing deactivation seems impossible, at least for now, with more advances such as the ones highlighted in this review, reducing it to the barest minimum is attainable. 
Acknowledgments: This study was carried out with the aid of a research grant from Fundamental Research Grant Scheme (FRGS) (project no. FP031-2013A) under the University of Malaya.

\section{References}

Aguado J, Serrano D, Rodriguez J. Zeolite beta with hierarchical porosity prepared from organofunctionalized seeds. Microporous Mesoporous Mater 2008; 115: 504-513.

Al-Shammari AA, Ali SA, Al-Yassir N, Aitani AM, Ogunronbi KE, Al-Majnouni KA, Al-Khattaf SS. Catalytic cracking of heavy naphtha-range hydrocarbons over different zeolites structures. Fuel Process Technol 2014; 122: 12-22.

Apaydin-Varol E, Uzun BB, Önal E, Pütün AE. Synthetic fuel production from cottonseed: fast pyrolysis and a TGA/FT-IR/MS study. J Anal Appl Pyrolysis 2014; 105: 83-90.

Balat M. New biofuel production technologies. Energy Educ Sci Technol Part A 2009; 22: 147-161.

Bartholomew CH. Mechanisms of catalyst deactivation. Appl Catal A Gen 2001; 212: 17-60.

Barthomeuf D. Basic zeolites: characterization and uses in adsorption and catalysis. Catal Rev 1996; 38: 521-612.

Beauchet R, Pinard L, Kpogbemabou D, Laduranty J, Lemee L, Lemberton J, Bataille F, Magnoux P, Ambles A, Barbier J. Hydroliquefaction of green wastes to produce fuels. Bioresour Technol 2011; 102: 6200-6207.

Bedard J, Chiang H, Bhan A. Kinetics and mechanism of acetic acid esterification with ethanol on zeolites. J Catal 2012; 290: 210-219.

Bjørgen M, Joensen F, Spangsberg Holm M, Olsbye U, Lillerud K-P, Svelle S. Methanol to gasoline over zeolite H-ZSM-5: improved catalyst performance by treatment with $\mathrm{NaOH}$. Appl Catal A Gen 2008; 345: 43-50.

Botas J, Serrano D, García A, de Vicente J, Ramos R. Catalytic conversion of rapeseed oil into raw chemicals and fuels over $\mathrm{Ni}$ - and Mo-modified nanocrystalline ZSM- 5 zeolite. Catal Today 2012; 195: 59-70.

Botas J, Serrano DP, García A, Ramos R. Catalytic conversion of rapeseed oil for the production of raw chemicals, fuels and carbon nanotubes over Ni-modified nanocrystalline and hierarchical ZSM-5. Appl Catal B 2014; 145: 205-215.

Bozell JJ, Petersen GR. Technology development for the production of biobased products from biorefinery carbohydrates - the US Department of Energy's “top 10” revisited. Green Chem 2010; 12: 539-554.

Caeiro G, Magnoux P, Lopes J, Ribeiro FR, Menezes S, Costa A, Cerqueira $\mathrm{H}$. Stabilization effect of phosphorus on steamed H-MFI zeolites. Appl Catal A Gen 2006; 314: 160-171.

Castano P, Elordi G, Olazar M, Aguayo AT, Pawelec B, Bilbao J. Insights into the coke deposited on HZSM-5, $\mathrm{H} \beta$ and $\mathrm{HY}$ zeolites during the cracking of polyethylene. Appl Catal B 2011; 104: 91-100.

Castaño P, Ruiz-Martínez J, Epelde E, Gayubo AG, Weckhuysen BM. Spatial distribution of zeolite ZSM-5 within catalyst bodies affects selectivity and stability of methanol-to-hydrocarbons conversion. ChemCatChem 2013; 5: 2827-2831.
Charusiri W, Yongchareon W, Vitidsant T. Conversion of used vegetable oils to liquid fuels and chemicals over HZSM-5, sulfated zirconia and hybrid catalysts. Korean J Chem Eng 2006; 23: 349-355.

Chen F, Ma L, Cheng D-g, Zhan X. Synthesis of hierarchical porous zeolite and its performance in $\mathrm{n}$-heptane cracking. Catal Commun 2012; 18: 110-114.

Chew TL, Bhatia S. Effect of catalyst additives on the production of biofuels from palm oil cracking in a transport riser reactor. Bioresour Technol 2009; 100: 2540-2545.

Choi J, Jeong H-K, Snyder MA, Stoeger JA, Masel RI, Tsapatsis M. Grain boundary defect elimination in a zeolite membrane by rapid thermal processing. Science 2009; 325: 590-593.

Corma A, Huber GW, Sauvanaud L, O'Connor P. Processing biomassderived oxygenates in the oil refinery: catalytic cracking (FCC) reaction pathways and role of catalyst. J Catal 2007; 247: 307-327.

Demirbas A. Products from lignocellulosic materials via degradation processes. Energy Sources Part A 2007a; 30: 27-37.

Demirbas A. Combustion systems for biomass fuel. Energy Sources Part A 2007b; 29: 303-312.

Demirbas A. Combustion of biomass. Energy Sources Part A 2007c; 29: 549-561.

Demirbas A. Conversion of corn stover to chemicals and fuels. Energy Sources Part A 2008a; 30: 788-796.

Demirbas A. Liquefaction of biomass using glycerol. Energy Sources Part A 2008b; 30: 1120-1126.

Demirbas A. Biofuels securing the planet's future energy needs. Energy Convers Manag 2009; 50: 2239-2249.

Deng X, Fang Z, Liu Y-h, Yu C-L. Production of biodiesel from Jatropha oil catalyzed by nanosized solid basic catalyst. Energy 2011; 36: 777-784.

Derewinski M, Sarv P, Sun X, Müller S, Van Veen AC, Lercher JA. On the reversibility of the modification of $\mathrm{HZSM}-5$ with phosphate anions. J Phys Chem C 2014; 118: 6122-6131.

Duan C, Zhang X, Zhou R, Hua Y, Zhang L, Chen J. Comparative studies of ethanol to propylene over HZSM-5/SAPO-34 catalysts prepared by hydrothermal synthesis and physical mixture. Fuel Process Technol 2013; 108: 31-40.

Eberly Jr P, Kimberlin Jr C, Miller W, Drushel H. Coke formation on silica-alumina cracking catalysts. Ind Eng Chem Process Des Dev 1966; 5: 193-198.

Fan W, Snyder MA, Kumar S, Lee P-S, Yoo WC, McCormick AV, Penn RL, Stein A, Tsapatsis M. Hierarchical nanofabrication of microporous crystals with ordered mesoporosity. Nat Mater 2008; 7: 984-991.

Francesconi MS, López ZE, Uzcátegui D, González G, Hernández JC, Uzcátegui A, Loaiza A, Imbert FE. MFI/MEL intergrowth and its effect on $n$-decane cracking. Catal Today 2005; 107 : 809-815.

Gayubo A, Valle B, Aguayo A, Olazar M, Bilbao J. Pyrolytic lignin removal for the valorization of biomass pyrolysis crude bio-oil by catalytic transformation. J Chem Technol Biotechnol 2010; 85: 132-144.

Gayubo AG, Valle B, Aguayo AT, Olazar M, Bilbao J. Olefin production by catalytic transformation of crude bio-oil in a two-step process. Ind Eng Chem Res 2009; 49: 123-131.

Gerçel H, Gerçel Ö. Bio-oil production from an oilseed by-product: fixed-bed pyrolysis of olive cake. Energy Sources Part A 2007; 29: 695-704. 
Gómez JM, Romero MD, Callejo V. Heterogeneous basic catalysis for upgrading of biofuels. Catal Today 2013; 218: 143-147.

González G, González CS, Stracke W, Reichelt R, García L. New zeolite topologies based on intergrowths of FAU/EMT systems. Microporous Mesoporous Mater 2007; 101: 30-42.

Gonzalez J, Kim M, Buonomo E, Bonelli P, Cukierman A. Pyrolysis of biomass from sustainable energy plantations: effect of mineral matter reduction on kinetics and charcoal pore structure. Energy Sources Part A 2008; 30: 809-817.

Graça I, Fernandes A, Lopes J, Ribeiro M, Laforge S, Magnoux P, Ramôa Ribeiro F. Effect of phenol adsorption on HY zeolite for n-heptane cracking: comparison with methylcyclohexane. Appl Catal A Gen 2010; 385: 178-189.

Hajek J, Kumar N, Nieminen V, Mäki-Arvela P, Salmi T, Murzin DY, Červený L. Deactivation in liquid-phase hydrogenation of cinnamaldehyde over alumosilicate-supported ruthenium and platinum catalysts. Chem Eng J 2004; 103: 35-43.

Hartmann M. Hierarchical zeolites: a proven strategy to combine shape selectivity with efficient mass transport. Angew Chem Int Ed 2004; 43: 5880-5882.

Heeres H, Handana R, Chunai D, Rasrendra CB, Girisuta B, Heeres HJ. Combined dehydration/(transfer)-hydrogenation of C6-sugars (D-glucose and D-fructose) to $\gamma$-valerolactone using ruthenium catalysts. Green Chem 2009; 11: 1247-1255.

Holm MS, Taarning E, Egeblad K, Christensen CH. Catalysis with hierarchical zeolites. Catal Today 2011; 168: 3-16.

Hong Z, Wu Z, Zhang Y, Gu X. Catalytic cracking deposition of methyldiethoxysilane for modification of zeolitic pores in $\mathrm{MFI} / \alpha-\mathrm{Al} 203$ zeolite membrane with $\mathrm{H}+$ ion exchange pretreatment. Ind Eng Chem Res 2013; 52: 13113-13119.

Huang J, Long W, Agrawal PK, Jones CW. Effects of acidity on the conversion of the model bio-oil ketone cyclopentanone on H- Y zeolites. J Phys Chem C 2009; 113: 16702-16710.

Huber GW, Corma A. Synergies between bio- and oil refineries for the production of fuels from biomass. Angew Chem Int Ed 2007; 46: 7184-7201.

Huber GW, Iborra S, Corma A. Synthesis of transportation fuels from biomass: chemistry, catalysts, and engineering. Chem Rev 2006; 106: 4044-4098.

Ibáñez M, Valle B, Bilbao J, Gayubo AG, Castaño P. Effect of operating conditions on the coke nature and HZSM-5 catalysts deactivation in the transformation of crude bio-oil into hydrocarbons. Catal Today 2012; 195: 106-113.

Ibáñez M, Artetxe M, Lopez G, Elordi G, Bilbao J, Olazar M, Castaño P. Identification of the coke deposited on an HZSM-5 zeolite catalyst during the sequenced pyrolysis-cracking of HDPE. Appl Catal B 2014; 148: 436-445.

Ishihara A, Inui K, Hashimoto T, Nasu H. Preparation of hierarchical $\beta$ and $Y$ zeolite-containing mesoporous silica-aluminas and their properties for catalytic cracking of $n$-dodecane. J Catal 2012; 295: 81-90.

Iwakai K, Tago T, Konno H, Nakasaka Y, Masuda T. Preparation of nano-crystalline MFI zeolite via hydrothermal synthesis in water/surfactant/organic solvent using fumed silica as the $\mathrm{Si}$ source. Microporous Mesoporous Mater 2011; 141: 167-174.

Jacobson K, Maheria KC, Kumar Dalai A. Bio-oil valorization: a review. Renew Sustain Energy Rev 2013; 23: 91-106.

Jiménez-García G, Lasa Hd, Quintana-Solórzano R, Maya-Yescas R. Catalyst activity decay due to pore blockage during catalytic cracking of hydrocarbons. Fuel 2013; 110: 89-98.
Kang S-H, Ryu J-H, Kim J-H, Jang IH, Kim AR, Han GY, Bae JW, Ha K-S. Role of ZSM5 distribution on $\mathrm{Co} / \mathrm{SiO}_{2}$ Fischer-Tropsch catalyst for the production of C5-C22 hydrocarbons. Energy Fuels 2012; 26: 6061-6069.

Karki S, Mann M, Salehfar H. Environmental implications of renewable distributed generation technologies in rural electrification. Energy Sources Part B 2008; 3: 186-195.

Kawai T, Tsutsumi K. Evaluation of hydrophilic-hydrophobic character of zeolites by measurements of their immersional heats in water. Colloid Polym Sci 1992; 270: 711-715.

Kim J, Choi M, Ryoo R. Effect of mesoporosity against the deactivation of MFI zeolite catalyst during the methanol-tohydrocarbon conversion process. J Catal 2010; 269: 219-228.

Kim K, Ryoo R, Jang H-D, Choi M. Spatial distribution, strength, and dealumination behavior of acid sites in nanocrystalline MFI zeolites and their catalytic consequences. J Catal 2012; 288: 115-123.

Koekkoek AJ, Tempelman CH, Degirmenci V, Guo M, Feng Z, Li C, Hensen EJ. Hierarchical zeolites prepared by organosilane templating: a study of the synthesis mechanism and catalytic activity. Catal Today 2011; 168: 96-111.

Konno H, Okamura T, Kawahara T, Nakasaka Y, Tago T, Masuda T. Kinetics of $n$-hexane cracking over ZSM- 5 zeolites - effect of crystal size on effectiveness factor and catalyst lifetime. Chem Eng J 2012; 207: 490-496.

Konno H, Tago T, Nakasaka Y, Ohnaka R, Nishimura J-i, Masuda T. Effectiveness of nano-scale ZSM-5 zeolite and its deactivation mechanism on catalytic cracking of representative hydrocarbons of naphtha. Microporous Mesoporous Mater 2013; 175: 25-33.

Kresge C, Leonowicz M, Roth W, Vartuli J, Beck J. Ordered mesoporous molecular sieves synthesized by a liquid-crystal template mechanism. Nature 1992; 359: 710-712.

Kumbilieva K, Petrov L, Alhamed Y, Alzahrani A. Reaction mechanism and deactivation modes of heterogeneous catalytic systems. Chinese J Catal 2011; 32: 387-404.

Le Van Mao R, Melancon S, Gauthier-Campbell C, Kletnieks P. Selective deep catalytic cracking process (SDCC) of petroleum feedstocks for the production of light olefins. I. The Catlever effect obtained with a two reaction-zones system on the conversion of n-hexane. Catal Lett 2001; 73: 181-186.

Le Van Mao R, Vu N-T, Al-Yassir N, François N, Monnier J. The thermocatalytic cracking process for the production of light olefins and transportation fuels from gas oils. Topics Catal 2006; 37: 107-112.

Le Van Mao R, Vu N, Al-Yassir N, Yan H. Effect of the spilt-over hydrogen species on the product yields of the hybrid catalysts used in the thermocatalytic cracking (TCC) process for the production of light olefins. Ind Eng Chem Res 2008; 47: 2963-2969.

Li J, Li X, Zhou G, Wang W, Wang C, Komarneni S, Wang Y. Catalytic fast pyrolysis of biomass with mesoporous ZSM- 5 zeolites prepared by desilication with $\mathrm{NaOH}$ solutions. Appl Catal A Gen 2014a; 470: 115-122.

Li T, Duan A, Zhao Z, Liu B, Jiang G, Liu J, Wei Y, Pan H. Synthesis of ordered hierarchically porous L-SBA-15 material and its hydro-upgrading performance for FCC gasoline. Fuel 2014b; 117: 974-980.

Liu Y, Zhang W, Xie S, Xu L, Han X, Bao X. Probing the porosity of cocrystallized MCM-49/ZSM-35 zeolites by hyperpolarized 129Xe NMR. J Phys Chem B 2008; 112: 1226-1231. 
Liu G, Zhao G, Meng F, Qu S, Wang L, Zhang X. Catalytic cracking of supercritical n-dodecane over wall-coated HZSM-5 zeolites with micro-and nanocrystal sizes. Energy Fuels 2012; 26: 1220-1229.

Louis B, Vicente Al, Fernandez C, Valtchev V. Crystal size-acid sites relationship study of nano- and micrometer-sized zeolite crystals. J Phys Chem C 2011; 115: 18603-18610.

Mante OD, Agblevor F, Oyama S, McClung R. Catalytic pyrolysis with ZSM- 5 based additive as co-catalyst to Y-zeolite in two reactor configurations. Fuel 2014; 117: 649-659.

Martínez A, Rollán J, Arribas MA, Cerqueira HS, Costa AF, S-Aguiar EF. A detailed study of the activity and deactivation of zeolites in hybrid $\mathrm{Co} / \mathrm{SiO}_{2}$-zeolite Fischer-Tropsch catalysts. J Catal 2007; 249: 162-173.

Martínez A, Valencia S, Murciano R, Cerqueira HS, Costa AF, S-Aguiar EF. Catalytic behavior of hybrid $\mathrm{Co} / \mathrm{SiO}_{2}{ }^{-}$ (medium-pore) zeolite catalysts during the one-stage conversion of syngas to gasoline. Appl Catal A Gen 2008; 346: $117-125$.

Masuda T, Fukumoto N, Kitamura M, Mukai SR, Hashimoto K, Tanaka T, Funabiki T. Modification of pore size of MFI-type zeolite by catalytic cracking of silane and application to preparation of $\mathrm{H}_{2}$-separating zeolite membrane. Microporous Mesoporous Mater 2001; 48: 239-245.

Mei C, Wen P, Liu Z, Liu H, Wang Y, Yang W, Xie Z, Hua W, Gao Z. Selective production of propylene from methanol: mesoporosity development in high silica HZSM-5. J Catal 2008; 258: 243-249.

Melancon S, Le Van Mao R, Kletnieks P, Ohayon D, Intem S, Saberi M, McCann D. Selective deep catalytic cracking process of hydrocarbon feedstocks for the production of light olefins: II. Cooperative effect of thermal cracking and catalytic reactions observed in a 1-zone reactor. Catal Lett 2002; 80: 103-109.

Menon P. Coke on catalysts-harmful, harmless, invisible and beneficial types. J Mol Catal 1990; 59: 207-220.

Mentzel UV, Holm MS. Utilization of biomass: conversion of model compounds to hydrocarbons over zeolite H-ZSM-5. Appl Catal A Gen 2011; 396: 59-67.

Mohammad M, Kandaramath Hari T, Yaakob Z, Chandra Sharma Y, Sopian K. Overview on the production of paraffin based-biofuels via catalytic hydrodeoxygenation. Renew Sustain Energy Rev 2013; 22: 121-132.

Mortensen PM, Grunwaldt J-D, Jensen PA, Knudsen K, Jensen AD. A review of catalytic upgrading of bio-oil to engine fuels. Appl Catal A Gen 2011; 407: 1-19.

Moulijn J, Van Diepen A, Kapteijn F. Catalyst deactivation: is it predictable?: What to do? Appl Catal A Gen 2001; 212: 3-16.

Muntasar A, Le Van Mao R, Yan H. "Petroleum gas oil-ethanol” blends used as feeds: increased production of ethylene and propylene over catalytic steam-cracking (CSC) hybrid catalysts. Different behavior of methanol in blends with petroleum gas oil. Ind Eng Chem Res 2010; 49: 3611-3616.

Na K, Jo C, Kim J, Cho K, Jung J, Seo Y, Messinger RJ, Chmelka BF, Ryoo R. Directing zeolite structures into hierarchically nanoporous architectures. Science 2011; 333: 328-332.

Na K, Choi M, Ryoo R. Recent advances in the synthesis of hierarchically nanoporous zeolites. Microporous Mesoporous Mater 2013; 166: 3-19.

Niwa M, Morishita N, Tamagawa H, Katada N. HZSM-5 treated with ammonia and water vapor: characterization and cracking activity. Catal Today 2012a; 198: 12-18.
Niwa M, Sota S, Katada N. Strong Brønsted acid site in HZSM- 5 created by mild steaming. Catal Today 2012b; 185 : 17-24.

O'Connor P, Pouwels A. FCC catalyst deactivation: a review and directions for further research. Stud Surf Sci Catal 1994; 88: 129-144.

Park HJ, Heo HS, Jeon J-K, Kim J, Ryoo R, Jeong K-E, Park Y-K. Highly valuable chemicals production from catalytic upgrading of radiata pine sawdust-derived pyrolytic vapors over mesoporous MFI zeolites. Appl Catal B 2010; 95: 365-373.

Perez-Ramirez J, Christensen CH, Egeblad K, Christensen CH, Groen JC. Hierarchical zeolites: enhanced utilisation of microporous crystals in catalysis by advances in materials design. Chem Soc Rev 2008; 37: 2530-2542.

Pérez-Ramírez J, Verboekend D, Bonilla A, Abelló S. Zeolite catalysts with tunable hierarchy factor by pore-growth moderators. Adv Funct Mater 2009; 19: 3972-3979.

Phung TK, Casazza AA, Aliakbarian B, Finocchio E, Perego P. Catalytic conversion of ethyl acetate and acetic acid on alumina as models of vegetable oils conversion to biofuels. Chem Eng J 2013; 215: 838-848.

Prasomsri T, To AT, Crossley S, Alvarez WE, Resasco DE. Catalytic conversion of anisole over HY and HZSM- 5 zeolites in the presence of different hydrocarbon mixtures. Appl Catal B 2011; 106: 204-211.

Pütün E, Uzun BB, Pütün AE. Fixed-bed catalytic pyrolysis of cotton-seed cake: effects of pyrolysis temperature, natural zeolite content and sweeping gas flow rate. Bioresour Technol 2006; 97: 701-710.

Pütün E, Uzun BB, Pütün AE. Rapid pyrolysis of olive residue. 2. Effect of catalytic upgrading of pyrolysis vapors in a two-stage fixed-bed reactor. Energy Fuels 2009; 23: 2248-2258.

Quadrelli R, Peterson S. The energy-climate challenge: recent trends in $\mathrm{CO}_{2}$ emissions from fuel combustion. Energy Policy 2007; 35: 5938-5952.

Rezaei PS, Shafaghat H, Daud WMAW. Production of green aromatics and olefins by catalytic cracking of oxygenate compounds derived from biomass pyrolysis: a review. Appl Catal A Gen 2014; 469: 490-511.

Rownaghi AA, Rezaei F, Hedlund J. Selective formation of light olefin by $n$-hexane cracking over HZSM-5: influence of crystal size and acid sites of nano- and micrometer-sized crystals. Chem Eng J 2012; 191: 528-533.

Sandeep K. Saxena NV. Selective production of green gasoline by catalytic conversion of Jatropha oil. Fuel Process Technol 2014; 119: 158-165.

Sani YM, Daud WMAW, Abdul Aziz A. Activity of solid acid catalysts for biodiesel production: a critical review. Appl Catal A Gen 2014; 470: 140-161.

Serrano-Ruiz JC, Pineda A, Balu AM, Luque R, Campelo JM, Romero AA, Ramos-Fernández JM. Catalytic transformations of biomass-derived acids into advanced biofuels. Catal Today 2012; 195: 162-168.

Shan L, Shao J, Wang Z, Yan Y. Preparation of zeolite MFI membranes on alumina hollow fibers with high flux for pervaporation. J Membrane Sci 2011; 378: 319-329.

Shi H, Chen J, Yang Y, Tian S. Catalytic deoxygenation of methyl laurate as a model compound to hydrocarbons on nickel phosphide catalysts: remarkable support effect. Fuel Process Technol 2014; 118: 161-170. 
Sooknoi T, Danuthai T, Lobban LL, Mallinson RG, Resasco DE. Deoxygenation of methylesters over CsNaX. J Catal 2008; 258: 199-209.

Sun Y, Prins R. Friedel-Crafts alkylations over hierarchical zeolite catalysts. Appl Catal A Gen 2008; 336: 11-16.

Tago T, Iwakai K, Morita K, Tanaka K, Masuda T. Control of acid-site location of ZSM- 5 zeolite membrane and its application to the MTO reaction. Catal Today 2005; 105: 662-666.

Tago T, Konno H, Sakamoto M, Nakasaka Y, Masuda T. Selective synthesis for light olefins from acetone over ZSM- 5 zeolites with nano- and macro-crystal sizes. Appl Catal A Gen 2011; 403: 183-191.

Tang Y, Miao S, Shanks BH, Zheng X. Bifunctional mesoporous organic-inorganic hybrid silica for combined one-step hydrogenation/esterification. Appl Catal A Gen 2010; 375: 310-317.

Taufiqurrahmi N, Mohamed AR, Bhatia S. Deactivation and coke combustion studies of nanocrystalline zeolite beta in catalytic cracking of used palm oil. Chem Eng J 2010; 163: 413-421.

Taufiqurrahmi N, Mohamed AR, Bhatia S. Production of biofuel from waste cooking palm oil using nanocrystalline zeolite as catalyst: process optimization studies. Bioresour Technol 2011; 102: 10686-10694.

Teng H, Wang J, Chen D, Liu P, Wang X. Silicalite-1 membrane on millimeter-sized HZSM- 5 zeolite extrudates: controllable synthesis and catalytic behavior in toluene disproportionation. J Membrane Sci 2011; 381: 197-203.

Tian D, Yan W, Wang Z, Wang Y, Li Z, Yu J, Xu R. Core-shell composite of Ti-/Cr-AFI molecular sieve via solvothermal epitaxial growth. Crystal Growth Design 2009; 9: 1411-1414.

Tsai T-C, Wang I, Huang C-K, Liu S-D. Study on ethylbenzene and xylene conversion over modified ZSM-5. Appl Catal A Gen 2007; 321: 125-134.

Twaiq FA, Zabidi NA, Bhatia S. Catalytic conversion of palm oil to hydrocarbons: performance of various zeolite catalysts. Ind Eng Chem Res 1999; 38: 3230-3237.

Valle B, Castaño P, Olazar M, Bilbao J, Gayubo AG. Deactivating species in the transformation of crude bio-oil with methanol into hydrocarbons on a HZSM-5 catalyst. J Catal 2012; 285: 304-314.

Van Santen R. Theory of Brønsted acidity in zeolites. Stud Surf Sci Catal 1994; 85: 273-294.

Varzaneh AZ, Kootenaei AHS, Towfighi J, Mohamadalizadeh A. Optimization and deactivation study of $\mathrm{Fe}-\mathrm{Ce} / \mathrm{HZSM}-5$ catalyst in steam catalytic cracking of mixed ethanol/naphtha feed. J Anal Appl Pyrolysis 2013; 102: 144-153.

Viswanadham N, Saxena SK, Kumar J, Sreenivasulu P, Nandan D. Catalytic performance of nano crystalline H-ZSM- 5 in ethanol to gasoline (ETG) reaction. Fuel 2012; 95: 298-304.

Wang H, Lin Y. Effects of synthesis conditions on MFI zeolite membrane quality and catalytic cracking deposition modification results. Microporous Mesoporous Mater 2011; 142: 481-488.

Wang H, Lin Y. Synthesis and modification of ZSM-5/silicalite bilayer membrane with improved hydrogen separation performance. J Membrane Sci 2012; 396: 128-137.

Wang P, Shen B, Gao J. Synthesis of MAZ/ZSM-5 composite zeolite and its catalytic performance in $\mathrm{FCC}$ gasoline aromatization. Catal Commun 2007; 8: 1161-1166.

Wang L, Zhang Z, Yin C, Shan Z, Xiao F-S. Hierarchical mesoporous zeolites with controllable mesoporosity templated from cationic polymers. Microporous Mesoporous Mater 2010; 131: 58-67.

Wang H, Dong X, Lin Y. Highly stable bilayer MFI zeolite membranes for high temperature hydrogen separation. J Membrane Sci 2014; 450: 425-432.

Whiting GT, Meirer F, Mertens MM, Bons AJ, Weiss BM, Stevens PA, de Smit E, Weckhuysen BM. Binder effects in $\mathrm{SiO}_{2}$ - and $\mathrm{Al}_{2} \mathrm{O}_{3}$-bound zeolite ZSM-5-based extrudates as studied by microspectroscopy. ChemCatChem 2015; 7: 1312-1321.

Xie Z, Liu Z, Wang Y, Yang Q, Xu L, Ding W. An overview of recent development in composite catalysts from porous materials for various reactions and processes. Int J Mol Sci 2010; 11: 2152-2187.

Xu L, Wu S, Guan J, Wang H, Ma Y, Song K, Xu H, Xing H, Xu C, Wang Z. Synthesis, characterization of hierarchical ZSM- 5 zeolite catalyst and its catalytic performance for phenol tert-butylation reaction. Catal Commun 2008; 9: 1272-1276.

Xue N, Olindo R, Lercher JA. Impact of forming and modification with phosphoric acid on the acid sites of HZSM-5. J Phys Chem C 2010; 114: 15763-15770.

Xue Z, Ma J, Zhang T, Miao H, Li R. Synthesis of nanosized ZSM-5 zeolite with intracrystalline mesopores. Mater Lett 2012a; 68: 1-3.

Xue Z, Ma J, Zheng J, Zhang T, Kang Y, Li R. Hierarchical structure and catalytic properties of a microspherical zeolite with intracrystalline mesopores. Acta Materialia 2012b; 60: 5712-5722.

Yan H. The thermo-catalytic cracking of hydrocarbons: hybrid cartalyst configuration and the phenomena of hydrogen spill-over. Concordia University, 2009. (Doctoral dissertation).

Yan H. Mixed petroleum hydrocarbons and biomass derived compounds used in the thermal catalytic steam cracking (TCSC) process for the production of light olefins. Concordia University, 2013. (Doctoral dissertation).

Yan H, Le Van Mao R. The thermo-catalytic cracking of hydrocarbons: effect of polymethylbenzenes added to the $n$-hexane feed on the reactivity of ZSM- 5 zeolite containing hybrid catalyst. Catal Lett 2009; 130: 558-563.

Yan H, Le Van Mao R. Hybrid catalysts used in the catalytic steam cracking process (CSC): influence of the pore characteristics and the surface acidity properties of the ZSM- 5 zeolite-based component on the overall catalytic performance. Appl Catal A Gen 2010; 375: 63-69.

Yan H, Le Van Mao R. Catalytic compatibility of methanol with petroleum naphtha in mixed feeds used in the thermalcatalytic/steam-cracking (TCSC) process for the production of propylene and ethylene. Catal Lett 2012; 142: 60-70.

Ye J, Cao Q, Zhao Y. Co-pyrolysis of polypropylene and biomass. Energy Sources Part A 2008; 30: 1689-1697.

Yin C, Feng L, Ni R, Hu L, Zhao X, Tian D. One-pot synthesis of hierarchically nanoporous ZSM-5 for catalytic cracking. Powder Technol 2014; 253: 10-13.

Yiu HH, Wright PA. Enzymes supported on ordered mesoporous solids: a special case of an inorganic-organic hybrid. J Mater Chem 2005; 15: 3690-3700.

Yonli AH, Gener I, Mignard S. Comparative study of the hydrophobicity of BEA, HZSM- 5 and HY zeolites determined by competitive adsorption. Microporous Mesoporous Mater 2010; 132: 37-42.

Zapata PA, Faria J, Ruiz MP, Jentoft RE, Resasco DE. Hydrophobic zeolites for biofuel upgrading reactions at the liquid-liquid 
interface in water/oil emulsions. J Am Chem Soc 2012; 134: 8570-8578.

Zhang A, Nakamura I, Aimoto K, Fujimoto K. Isomerization of $n$-pentane and other light hydrocarbons on hybrid catalyst. Effect of hydrogen spillover. Ind Eng Chem Res 1995; 34: 1074-1080.

Zhang H, Cheng Y-T, Vispute TP, Xiao R, Huber GW. Catalytic conversion of biomass-derived feedstocks into olefins and aromatics with ZSM-5: the hydrogen to carbon effective ratio. Energy Environ Sci 2011; 4: 2297-2307.

Zhang Y, Wu Z, Hong Z, Gu X, Xu N. Hydrogen-selective zeolite membrane reactor for low temperature water gas shift reaction. Chem Eng J 2012; 197: 314-321.

Zhang H, Ma Y, Song K, Zhang Y, Tang Y. Nano-crystallite oriented self-assembled ZSM-5 zeolite and its LDPE cracking properties: effects of accessibility and strength of acid sites. J Catal 2013; 302: 115-125.

Zhang H, Luo M, Xiao R, Shao S, Jin B, Xiao G, Zhao M, Liang J. Catalytic conversion of biomass pyrolysis-derived compounds with chemical liquid deposition (CLD) modified ZSM-5. Bioresour Technol 2014; 155: 57-62.

Zhao D, Feng J, Huo Q, Melosh N, Fredrickson GH, Chmelka BF, Stucky GD. Triblock copolymer syntheses of mesoporous silica with periodic 50 to 300 angstrom pores. Science 1998; 279: 548-552.

Zheng J, Zeng Q, Zhang Y, Wang Y, Ma J, Zhang X, Sun W, Li R. Hierarchical porous zeolite composite with a core-shell structure fabricated using $\beta$-zeolite crystals as nutrients as well as cores. Chem Mater 2010; 22: 6065-6074.

Zheng J, Zeng Q, Yi Y, Wang Y, Ma J, Qin B, Zhang X, Sun W, Li R. The hierarchical effects of zeolite composites in catalysis. Catal Today 2011; 168: 124-132.

Zheng J, Yi Y, Wang W, Guo K, Ma J, Li R. Synthesis of bi-phases composite zeolites MFZ and its hierarchical effects in isopropylbenzene catalytic cracking. Microporous Mesoporous Mater 2013; 171: 44-52.

Zhu X, Mallinson RG, Resasco DE. Role of transalkylation reactions in the conversion of anisole over HZSM-5. Appl Catal A Gen 2010; 379: 172-181.

\section{Bionotes}

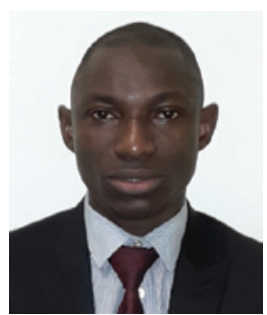

\section{Peter Adeniyi Alaba}

Department of Chemical Engineering, University of Malaya, 50603 Kuala Lumpur, Malaysia

Peter Adeniyi Alaba was an undergraduate at the Federal University of Technology Minna. He is currently carrying out his postgraduate studies at the University of Malaya under the supervision of Prof. Wan Mohd Ashri Wan Daud. He was appointed to a graduate research assistantship at the University of Malaya in 2013. His research interests lie in the rational design of tailored solid acid catalysts for efficient biofuel production.

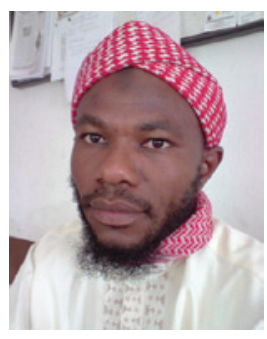

Yahaya Muhammad Sani

Department of Chemical Engineering, University of Malaya, 50603 Kuala Lumpur, Malaysia; and Department of Chemical Engineering, Ahmadu Bello University, 870001 Nigeria

Yahaya Muhammad Sani received his BEng chemical engineering degree from Ahmadu Bello University, the second largest on the African continent (2002), and MSc degrees in Biotechnology (Newcastle University, UK; 2007) and Chemical Engineering (A.B.U. Zaria; 2008) prior to obtaining a PhD from the University of Malaya, Malaysia. He joined A.B.U. Zaria in 2005 with research interest in catalysis and renewable and sustainable energy. He is a registered engineer certified by the Council for the Regulation of Engineering and a corporate member of the Nigerian Society of Engineers.

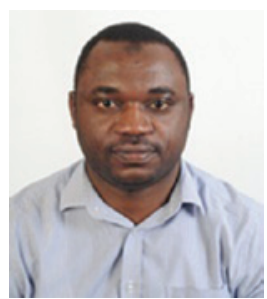

\section{Isah Yakub Mohammed}

Energy, Fuel and Power Technology Research Division, School of Engineering, The University of Nottingham Malaysia Campus, Jalan Broga, 43500 Semenyih, Selangor Darul Ehsan, Malaysia

Isah Yakub Mohammed obtained BEng and MSc degrees in Chemical Engineering from the Federal University of Technology Minna, Nigeria (2006) and the University of Nottingham, UK (2012). He is currently a PhD student in Chemical Engineering at University of Nottingham and a lecturer at Abubakar Tafawa Balewa University Bauchi, Nigeria. I.Y. Mohammed is a registered engineer with the Council for the Regulation of Engineering in Nigeria (COREN), a corporate member of the Nigerian Society of Engineers (NSE) and the Nigerian Society of Chemical Engineers (NSChE), a member of the American Institute of Chemical Engineers (AIChE), the International Water Association (IWA), and an associate member of the Institution of Chemical Engineers (IChemE).

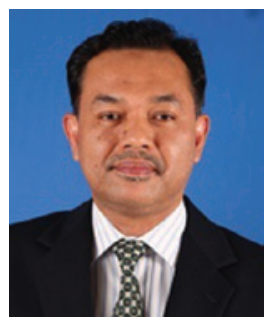

Wan Mohd Ashri Wan Daud

Department of Chemical Engineering, University of Malaya, 50603 Kuala Lumpur, Malaysia ashri@um.edu.my

Wan Mohd Ashri Wan Daud received his bachelor's degree in Chemical Engineering at Leeds University, Leeds, UK, in 1991 and his master's degree in Chemical Engineering at the University of Sheffield, Sheffield, UK, in 1993. He received his PhD degree in Chemical Engineering at the University of Sheffield in 1996. After 9 years as an academic and scientist at the Faculty of Engineering, he became a professor of Chemical Engineering in 2005. Since 2005, he has worked as a professor of Chemical Engineering at the University of Malaya, Malaysia. His research fields include energy, biomass conversion to bio-fuel, catalysts synthesis, polymerization and separation processes, and hydrogen storage. He has more than 131 publications in Web Science journals. 